\title{
Proteomic Analysis of Thermal Regulation of Small Yellow Follicles in Broiler-Type Taiwan Country Chickens
}

\author{
Chuen-Yu Cheng ${ }^{1}$, Wei-Lin $\mathrm{Tu}^{1}$, Chao-Jung Chen ${ }^{2,3}$, Hong-Lin Chan ${ }^{4,5}$, Chih-Feng Chen ${ }^{1,6,7}$, \\ Hsin-Hsin Chen ${ }^{1}$, Pin-Chi Tang ${ }^{1,2}$, Yen-Pai Lee ${ }^{1}$, Shuen-Ei Chen ${ }^{1,6,7}$ and San-Yuan Huang ${ }^{1,6,7,8}$ \\ ${ }^{1}$ Department of Animal Science, National Chung Hsing University, 145 Xingda Road, Taichung, 40227, Taiwan \\ ${ }^{2}$ Proteomic Core Laboratory, Department of Medical Research, China Medical University Hospital, \\ 91 Hsueh-Shih Road, Taichung, 40447, Taiwan \\ ${ }^{3}$ Graduate Institute of Integrated Medicine, China Medical University, 91 Hsueh-Shih Road, Taichung, 40402, Taiwan \\ ${ }^{4}$ Institute of Bioinformatics and Structural Biology, National Tsing Hua University, \\ 101 Section 2 Kuang-Fu Road, Hsinchu, 30013, Taiwan \\ ${ }^{5}$ Department of Medical Sciences, National Tsing Hua University, 101 Section 2 Kuang-Fu Road, Hsinchu, 30013, Taiwan \\ ${ }^{6}$ Agricultural Biotechnology Center, National Chung Hsing University, 145 Xingda Road, Taichung, 40227, Taiwan \\ ${ }^{7}$ Center for the Integrative and Evolutionary Galliformes Genomics, iEGG Center, \\ National Chung Hsing University, 145 Xingda Road, Taichung, 40227, Taiwan \\ ${ }^{8}$ Research Center for Sustainable Energy and Nanotechnology, National Chung Hsing University, \\ 145 Xingda Road, Taichung, 40227, Taiwan
}

Heat stress hampers egg production and lowers fertility in layers. This study investigated global protein abundance in the small yellow follicles (SYFs, 6-8 mm diameter) of a broiler-type strain of Taiwan country chickens (TCCs) under acute heat stress. Twelve 30 -week-old TCC hens were allocated to a control group maintained at $25^{\circ} \mathrm{C}$, and to three acute heat-stressed groups subjected to $38^{\circ} \mathrm{C}$ for $2 \mathrm{~h}$ without recovery, with 2 -h recovery, or with 6-h recovery. Two-dimensional difference gel electrophoresis analysis identified 119 significantly differentially expressed proteins after acute heat exposure. Gene ontology analysis revealed that most of these proteins are involved in molecular binding (34\%), catalytic activity (23\%), and structural molecule activity (11\%), and participate in metabolic processes $(20 \%)$, cellular processes $(20 \%)$, and cellular component organization or biogenesis $(11 \%)$. Proteins associated with stress response and survival (HSP25, HSP47, HSP70, HSC70, HSPA9), cytoskeleton remodeling, mitochondrial metabolic process of ATP production, antioxidative defense (peroxiredoxin-6), cargo lipid export and delivery (vitellogenin, apolipoprotein B and A1), and toxin/metabolite clearance and delivery (albumin) were upregulated after acute heat stress in the SYFs of TCCs. No overt cell death and atresia were observed in SYFs after acute heat stress. Collectively, these responses may represent a protective mechanism to maintain follicle cell integrity and survival, thereby ensuring a sufficient pool of SYFs for selection into the ovulation hierarchy for successful egg production.

Key words: acute heat stress, proteome, small yellow follicles, Taiwan country chickens

J. Poult. Sci., 55: 120-136, 2018

\section{Introduction}

Heat stress disturbs oogenesis, oocyte maturation, fertil-

Received: May 4, 2017, Accepted: August 3, 2017

Released Online Advance Publication: September 25, 2017

Correspondence: San-Yuan Huang, Department of Animal Science, National Chung Hsing University, 145 Xingda Road, Taichung, 40227, Taiwan. (E-mail: syhuang@dragon.nchu.edu.tw)

Shuen-Ei Chen, Department of Animal Science, National Chung Hsing University, 145 Xingda Road, Taichung, 40227, Taiwan.

(E-mail: shueneic@dragon.nchu.edu.tw) ization, and embryo development and implantation rate in many female mammals (Hansen, 2009; Sakatani et al., 2012). In chickens, high ambient temperatures exert detrimental effects on the endocrine system and on reproductive performance (Rozenboim et al., 2007). An estimated 480,000 oocytes are present in the chick ovary at hatching, but only a few hundred oocytes are selected to reach maturity during the adult life of domestic chickens (Onagbesan et al., 2009). In domestic chickens, small follicles are classified by size and color as small white follicles (SWFs, $<1 \mathrm{~mm}$ in diameter), large white follicles (LWFs, 2-3 mm in diameter), small 
yellow follicles (SYFs, 5-10 $\mathrm{mm}$ in diameter), and 5-6 large yellow preovulatory follicles that are $9-40 \mathrm{~mm}$ in diameter (Robinson and Etches, 1986; Robinson et al., 1988; Onagbesan et al., 2009). The preovulatory follicles are the ones destined for egg formation (Onagbesan et al., 2009) while the SYFs are retained in a prehierarchical stage as a pool of developing follicles for selection into the ovulation hierarchy, and as such, are critically related to laying performance (Tan et al., 2010). Our previous studies showed that acute heat stress induced gene expression related to proteolytic disintegration of the structural matrix and inflammation damage as an adaptive response in the SYFs of broiler-type B strain Taiwan country chickens (TCCs) (Cheng et al., 2015). In the present study, proteomic analysis and morphological examination were used to determine the protein expression profile in the SYFs of broiler-type B strain TCCs in response to acute heat stress.

\section{Materials and Methods}

Experimental Animals, Conditions for Acute Heat Stress, and Sample Collection

Twelve 30-week-old B strain TCC hens selected for maturity and body weight as previously described (Kuo et al., 2005) were used in this study. The study was reviewed and approved by the Institutional Animal Care and Use Committee of National Chung Hsing University (Taichung, Taiwan; IACUC No. 102-06). The pullets were housed in individual cages at 18 weeks of age. All 12 hens reached maximum egg production at 30 weeks of age (Chen et al., 2007). The hens were kept in a climate chamber under a light:dark photoperiod of $14: 10 \mathrm{~h}$ at $25^{\circ} \mathrm{C}$ and $55 \%$ relative humidity (RH) for more than 2 weeks as an adaptation period before acute heat stress treatment. Feed and water were provided ad libitum.

After the adaptation period, hens were allocated to four groups ( $n=3$ in each group). The control group (CTL) was kept at $25^{\circ} \mathrm{C}$ and $55 \% \mathrm{RH}$ throughout the experiment. The other three groups included hens treated with acute heat stress at $38^{\circ} \mathrm{C}$ and $55 \% \mathrm{RH}$ for $2 \mathrm{~h}$ without recovery (H2R0), with recovery at $25^{\circ} \mathrm{C}$ for $2 \mathrm{~h}(\mathrm{H} 2 \mathrm{R} 2)$, or with recovery at $25^{\circ} \mathrm{C}$ for $6 \mathrm{~h}$ (H2R6). Hens were sacrificed at the end of treatment and SYFs were collected, frozen in liquid nitrogen, and stored at $-80^{\circ} \mathrm{C}$ until protein isolation. Functionally mature ovaries were identified based on morphology as described by Robinson and Etches (1986) and Onagbesan et al. (2009).

Two-dimensional Difference Gel Electrophoresis (2D-DIGE)

The sampled SYFs were sliced and washed in sucrose buffer $(10 \mathrm{mmol} / \mathrm{L}$ Tris/ $\mathrm{HCl}, 250 \mathrm{mmol}$ sucrose, $\mathrm{pH}$ 7) with centrifugation at $4^{\circ} \mathrm{C}(400 \times g, 5 \mathrm{~min}$, three times). The supernatants were collected and lysed in O'Farrell's lysis buffer (9.5 M urea, $2 \% \mathrm{NP}-40,2 \% \mathrm{v} / \mathrm{v}$ ampholyte $3-10$, and $65 \mathrm{mM}$ DTT). Protein samples were sonicated $(40 \mathrm{~W}, 10 \mathrm{~s}$, six times) to completely dissolve the proteins. Protein concentration was determined by Bradford protein assay (BioRad, Hercules, CA, USA). Equal protein amounts from each treatment (CTL, H2R0, H2R2, and H2R6) were pooled.
After speed vacuum drying (CVE-200D; EYELA, Tokyo, Japan), samples were dissolved in 2-DE lysis buffer ( $4 \% \mathrm{w} / \mathrm{v}$ CHAPS, $7 \mathrm{M}$ urea, $2 \mathrm{M}$ thiourea, $10 \mathrm{mM}$ Tris- $\mathrm{HCl}$, $\mathrm{pH} 8.3$, $1 \mathrm{mM}$ EDTA) for 2-D DIGE analysis.

2-D DIGE analysis was conducted as described previously (Wang et al., 2014). In brief, $100 \mathrm{mg}$ of proteins were labeled with $250 \mathrm{pmol}$ of $\mathrm{N}$-hydroxysuccinimidyl ester derivatives of one of the three cyanine dyes Cy2, Cy3, or Cy5 (GE Healthcare, Uppsala, Sweden), for comparison on the same gel, on ice in the dark for $30 \mathrm{~min}$. Reactions were stopped with an excess of free L-lysine for $10 \mathrm{~min}$. Samples from the four treatments were labeled with Cy 3 or Cy5 and mixed well. A pool of samples from each treatment was labeled with $\mathrm{Cy} 2$ as an internal control to facilitate image matching and cross-gel comparison. The Cy3-, Cy5-, and Cy2-labeled samples were analyzed in triplicate on eight gels. Each gel contained the pooled internal standard and samples of two treatment groups. The arrangement of samples is presented in Supplementary Table S1.

The sample solution were used to rehydrate the nonlinear immobilized $\mathrm{pH}$ gradient strips $(\mathrm{pH} 3-10,24 \mathrm{~cm})$ in the dark for at least $12 \mathrm{~h}$ and then isoelectrically focused for $62,500 \mathrm{~V}$ hour at $20^{\circ} \mathrm{C}$ using a Multiphor II apparatus (GE Healthcare). Strips were equilibrated in equilibration buffer $(6 \mathrm{M}$ urea, $30 \%$ glycerol, $1 \%$ SDS [w/v], $100 \mathrm{mM}$ Tris-HCl, $\mathrm{pH} 8.8$ ) containing $65 \mathrm{mM}$ dithiothreitol for $15 \mathrm{~min}$, and then in equilibration buffer with $240 \mathrm{mM}$ iodoacetamide for another $15 \mathrm{~min}$. The equilibrated strips were layered on top of a 12.5 $\%$ SDS-polyacrylamide gel and sealed with $0.5 \%(\mathrm{w} / \mathrm{v})$ agarose containing bromophenol blue. For second-dimension separation, electrophoresis was conducted at $10^{\circ} \mathrm{C}$ using an Ettan 12 gel tank (GE Healthcare) at $2 \mathrm{~W}$ per gel until the dye front completely ran off the gel. After electrophoresis, the gels were scanned with an Ettan DIGE Imager (GE Healthcare) and the protein spots were detected, normalized, and analyzed using DeCyder 2-D Differential Analysis Software version 7.0 (GE Healthcare). Spots with an $\geq 1.5$ average fold change in abundance and a $P$-value less than 0.05 were considered significantly different and were selected for protein identification.

For protein spot picking, aliquots of unlabeled proteins $(600 \mu \mathrm{g})$ were subjected to 2-DE separation. Gel staining was done as in our previous study (Wang et al., 2014). Briefly, gels were fixed in fixing solution $(30 \%$ ethanol and $2 \%$ phosphoric acid) at room temperature overnight. After washing three times with double distilled water for $30 \mathrm{~min}$, the gels were incubated in staining solution (34\% methanol, $17 \%$ ammonium sulfate, $3 \%$ phosphoric acid) for $1 \mathrm{~h}$, and then continuously stained with $0.5 \mathrm{~g} / \mathrm{L}$ colloidal Coomassie blue G250 for 3 days.

\section{Matrix-assisted Laser Desorption/ionization Time-of-flight Mass Spectrometry (MALDI-TOF) and MALDI-TOF/TOF MS}

Spots exhibiting significant changes were excised from the Coomassie blue-stained gels for in-gel protein digestion (Wang et al., 2014). The gel spots were washed three times in $50 \%$ acetonitrile with $10 \mathrm{mM}$ ammonium bicarbonate, de- 
hydrated in pure acetonitrile, and speed vacuum dried. The dried gel plugs were reswollen with $20 \mathrm{ng} / \mathrm{mL}$ trypsin (Promega, Madison, WI, USA) in $10 \mathrm{mM}$ ammonium bicarbonate at $4^{\circ} \mathrm{C}$ for $30 \mathrm{~min}$ and then immersed in $10 \mathrm{mM}$ ammonium bicarbonate. In-gel digestion was performed at $37^{\circ} \mathrm{C}$ for $16 \mathrm{~h}$. After digestion, peptide extracts were recovered by sonication twice in elution solution (50\% acetonitrile and 1\% trifluoroacetic acid). Peptide extracts from the same gel plug were pooled and stored at $20^{\circ} \mathrm{C}$ until analysis.

MALDI-TOF MS was carried out according to the procedures outlined in our previous report (Wang et al., 2014), with some modifications. An external peptide calibration standard containing angiotensin II $([\mathrm{M}+\mathrm{H}] \mathrm{p}$ 1046.54), angiotensin $\mathrm{I}([\mathrm{M}+\mathrm{H}]+1296.68)$, substance $\mathrm{P}([\mathrm{M}+\mathrm{H}]+$ 1347.74), bombesin $([\mathrm{M}+\mathrm{H}]+1619.82)$, ACTH clip 1 to $17([\mathrm{M}+\mathrm{H}]+2093.09)$, ACTH clip 18 to $39([\mathrm{M}+\mathrm{H}]+$ 2465.20), and Somatostatin $28([\mathrm{M}+\mathrm{H}]+3147.47)$ (Bruker Daltonics, Bremen, Germany) was used to calibrate the instrument. The spectra were acquired in reflectron mode. Mass was determined using FlexAnalysis 2.4 software (Bruker Daltonics). For protein identification, peptide masses were searched against a comprehensive nonredundant protein sequence database (NCBInr 20130524 version with 25,805,290 sequences and 891,5431,356 residues; SwissProt 2013_05 version with 540,052 and 191,770,152 residues) using BioTools 3.0 software (Bruker Daltonics) in combination with the Mascot program (Wang et al., 2014). The Anchor Chip target was further subjected to MALDI TOF/TOF analysis using a Bruker UltraFlex III MALDI-TOF/TOF MS (Bruker Daltonics) equipped with a delayed extraction ion source. The metastable ions generated by laser-induced decomposition in laser-induced forward transfer mode were analyzed. Protein identities were determined by searching for MS/MS spectra against the NCBInr database (NCBInr 20130524 version with $25,805,290$ sequences and 8,915,431,356 residues; SwissProt 2013_05 version with 540,052 and 191,770,152 residues) using Bio-Tools 3.0 in combination with Mascot.

\section{Western Blot Analysis}

Western blot analysis was conducted as previously described (Wang et al., 2014). Soluble proteins from chicken SYFs lysed in sample buffer $(62.5 \mathrm{mM}$ Tris- $\mathrm{HCl}$ [pH 6.8], $2 \%$ SDS, $10 \%$ glycerol, $5 \% \beta$-mercaptoethanol, and $0.002 \%$ bromophenol blue) were separated with a $\mathrm{TGX}^{\mathrm{TM}}$ Stain-Free FastCast $^{\mathrm{TM}}$ Acrylamide Starter Kit, 12\% (161-0184; Bio$\mathrm{Rad})$. After electrophoresis, proteins were transferred to Immun-Blot ${ }^{\circledR}$ Low Fluorescence PVDF membranes (Bio$\mathrm{Rad}$ ) and blocked in $20 \mathrm{mM}$ Tris- $\mathrm{HCl}(\mathrm{pH} 7.4), 0.5 \mathrm{M} \mathrm{NaCl}$, and $0.05 \%$ Tween-20 (TTBS) containing 3\% gelatin for $1 \mathrm{~h}$. The membranes were immunoblotted with a 1:1,000 diluted anti-heat-shock protein 70 (HSP70) rabbit polyclonal antibody (SPA-812; EnZo Life Science, Farmingdale, NY, USA) for $1 \mathrm{~h}$, a 1:1,000 diluted anti-heat shock cognate 70 (HSC70) rat polyclonal antibody (SPA-815; EnZo Life Science) for 1 h, a 1:400 diluted anti-heat shock protein 25 (HSP25) mouse polyclonal antibody (IAP-28; Abcam, Cambridge, MA, USA) for $1 \mathrm{~h}$, a 1:200 diluted anti-heat shock protein 47 (HSP47) rabbit polyclonal antibody (LC-B2151; LifeSpan BioSciences, Seattle, WA, USA) for $1 \mathrm{~h}$, a 1:500 diluted anti-peroxiredoxin-6 (PRDX6) rabbit polyclonal antibody (AV48267; Sigma, St. Louis, MO, USA), or a 1:200 diluted anti- $\beta$ tubulin (TUBB) rabbit polyclonal antibody (sc-9104; Santa Cruz Biotechnology, Dallas, TX, USA) for $1 \mathrm{~h}$. After washing in TTBS three times ( 5 min each), the membranes were incubated for $1 \mathrm{~h}$ with 1:5,000 diluted goat anti-mouse or goat anti-rabbit immunoglobulin $\mathrm{G}$ ( $\mathrm{IgG}$ ) conjugated with alkaline phosphatase (Sigma), matching the primary antibody used. Then, the membranes were washed four times in TTBS and developed using a buffer containing nitro blue tetrazolium and 5-bromo-4-chloro-3-indoyl phosphate (BioRad). To determine the densities of the immunoblotted protein bands, ImageJ software (Version 1.51f; LSU Health Sciences Center, New Orleans, LA, USA) was used. Protein abundances were obtained by normalizing the densities of the protein bands to that of the total protein with Image Lab software (Version 5.2.1; Bio-Rad).

\section{Hematoxylin-eosin Staining of SYFs}

Formalin (10\%)-fixed and paraffin-embedded blocks of SYF tissue were sectioned, deparaffinized, and rehydrated with xylene, $100 \%$ ethanol, $95 \%$ ethanol, $85 \%$ ethanol, $80 \%$ ethanol, $50 \%$ ethanol, and de-ionized water for $3 \mathrm{~min}$ each. Sections were stained with hematoxylin and eosin and examined using an Olympus BX51 microscope and a DP70 Digital Camera System (Olympus, Shinjuku-ku, Tokyo, Japan). The SYF layer types (theca interna, basement membrane, granulosa cell layer, perivitelline layer, and yolk spheres) were identified by their cell types and location following Barber et al. (1991).

\section{Terminal Deoxynucleotidyl Transferase dUTP Nick End Labeling (TUNEL) Assay}

SYF apoptosis was analyzed by TUNEL assay using an In Situ Cell Death Detection Kit (Cat. No. 11684795910; Roche, Mannheim, Germany). Paraffin-embedded SYFs were sectioned, deparaffinized, and rehydrated following the procedures used for hematoxylin-eosin staining. The sections were subjected to the TUNEL assay conducted according to the manufacturer's instructions. Signals were calibrated and quantified using ImageJ (Version 1.51f; LSU Health Sciences Center).

\section{Immunohistochemical Analysis of SYFs}

SYF sections were boiled in sodium citrate buffer $(0.05 \%$ Tween-20 in $0.01 \mathrm{M}$ sodium citrate, $\mathrm{pH}$ 6.0) for $10 \mathrm{~min}$ to enhance antigen retrieval. Endogenous peroxidase activity was quenched with $3 \% \mathrm{H}_{2} \mathrm{O}_{2}$ for $10 \mathrm{~min}$ and nonspecific binding was blocked with super block solution (ScyTek Laboratories, West Logan, UT, USA) for $20 \mathrm{~min}$. Then, sections were incubated with 1:100 diluted anti-HSP70 rabbit polyclonal antibody (SPA-812; EnZo Life Science) or antiHSP25 mouse polyclonal antibody (IAP-28; Abcam) at room temperature for $1 \mathrm{~h}$. After washing three times in PBST $(0.05 \%$ Tween-20 in PBS) for $5 \mathrm{~min}$, sections were incubated with goat anti-rabbit IgG $(\mathrm{H}+\mathrm{L})$ secondary antibody-Alexa Fluor 488 (A-11008; Thermo Fisher Scientific, Waltham, MA, USA), or goat anti-mouse IgG $(\mathrm{H}+\mathrm{L})$ secondary anti- 
body-Alexa Fluor 546 (A-11003; Thermo Fisher Scientific) for $30 \mathrm{~min}$. After washing with PBST three times, the cells were stained with 4', 6-diamidino-2-phenylindole (DAPI). To confirm the specificity of the antibodies, negative controls were subjected to the same procedure, except that the primary antibody was replaced by mouse, rat, or rabbit IgG (Vector Laboratories, Burlingame, CA, USA).

\section{Bioinformatics Analysis}

Proteins with significantly different expression among treatments were annotated with their subcellular distribution, biological processes, and molecular functions using the gene ontology database (http://www.geneontology.org/). Unique gene and protein names were uploaded and searched for annotations. To simplify the classification, the second or third level of the tree browser in the molecular functions was used. In addition, the Kyoto Encyclopedia of Genes and Genomes (KEGG) pathway database (http://www.genome. $\mathrm{jp} / \mathrm{kegg} /$ pathway.html) was used to identify functional pathways in which the significantly differentially expressed proteins (DEPs) participate.

\section{Statistical Analysis}

Mean relative protein expression values from 2D-DIGE and western blotting were analyzed by Student's $t$-test. TUNEL assay data were analyzed by one-way ANOVA using the General Linear Model Procedure. All data were analyzed with Statistical Analysis System software (SAS, 2010). $P<0.05$ was considered significant.
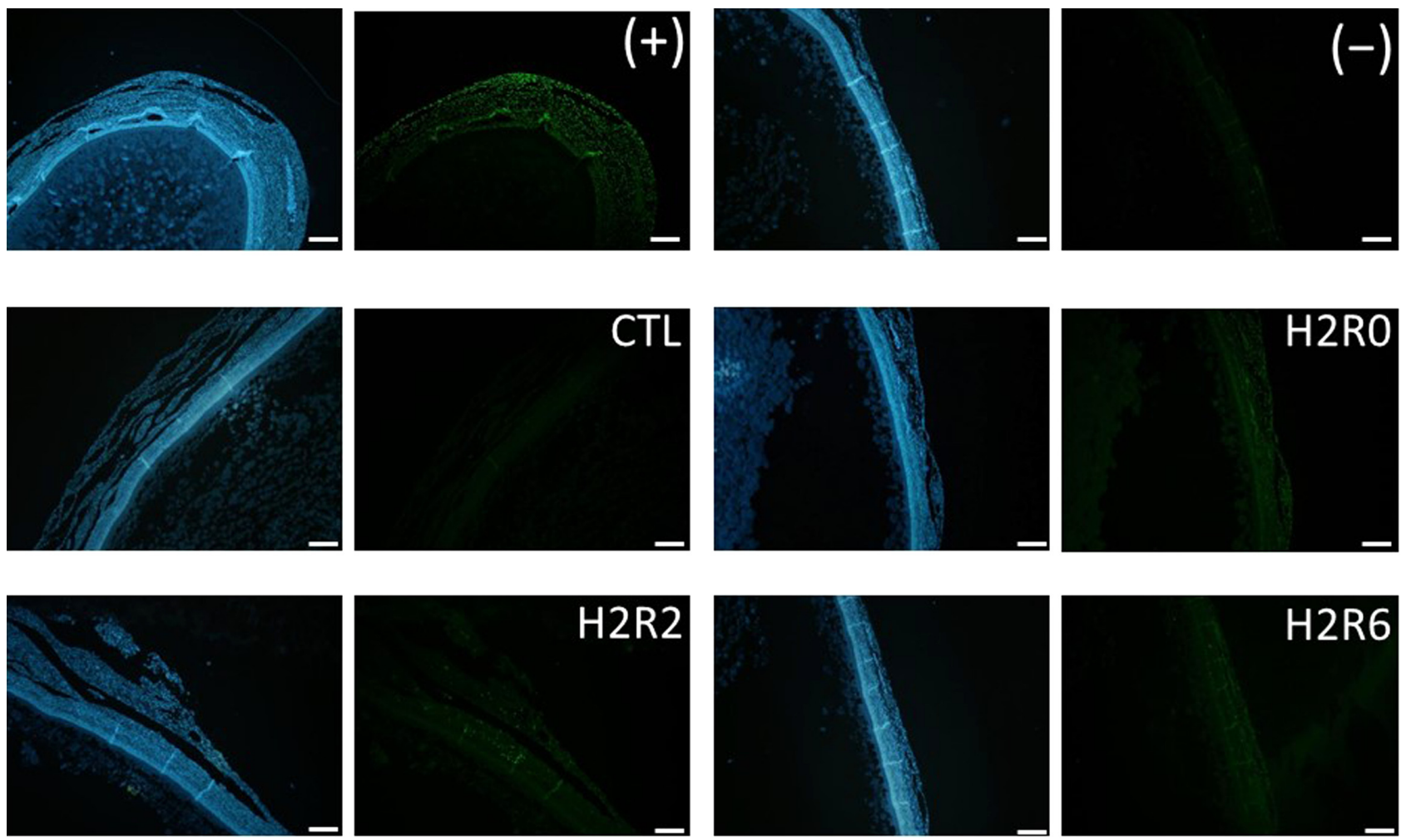

Fig. 1. TUNEL assay of SYFs of a broiler-type B strain TCCs. Columns 1 and 3, DAPI staining. Columns 2 and 4, TUNEL assay. Scale bar $=100 \mu \mathrm{m}$. 


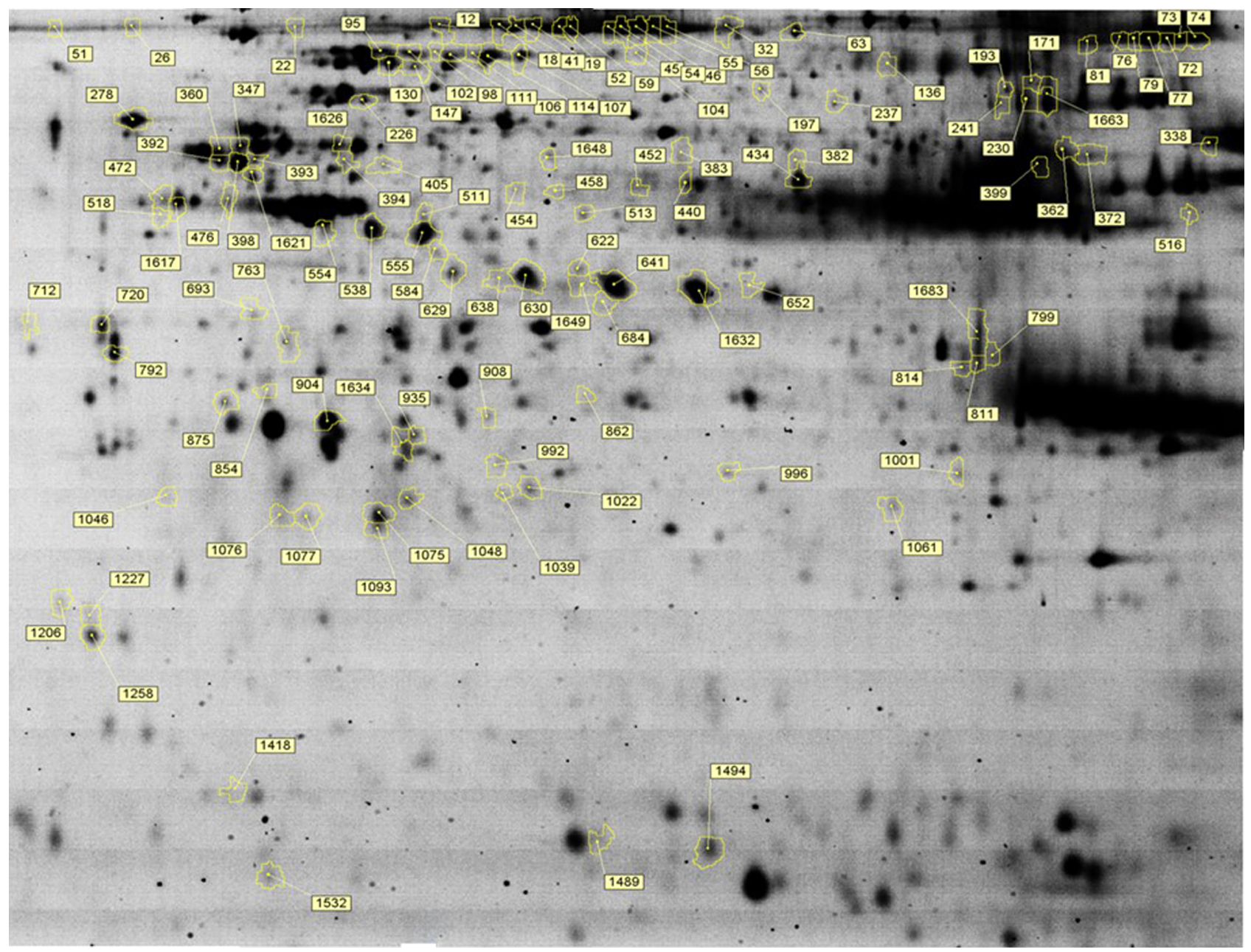

Fig. 2. 2D-DIGE protein profiles of SYFs of a broiler-type B strain TCCs. In total, 119 protein spots (indicated by yellow circles) showed significant differences in staining signal $(\geq 1.5, P<0.05)$ between control and heat-stressed groups.

binding (34\%), catalytic activity (23\%), and structural molecule activity $(11 \%)$, and participate in biological processes of metabolic processes $(20 \%)$, cellular processes $(20 \%)$, and cellular component organization or biogenesis (11\%) (Fig. 3 ). In view of functional annotation (Table 2), proteins involved in protein processing in the endoplasmic reticulum $(5.3 \%)$, endocytosis $(4.0 \%)$, glycolysis/gluconeogenesis $(2.6$ $\%)$, adipocytokine signaling $(1.3 \%)$, calcium signaling $(1.3$ $\%$, Fanconi anemia (1.3\%), MAPK signaling (1.3\%), and PPAR signaling (1.3\%) were upregulated after acute heat stress. Proteins related to ATP-binding cassette transporters (1.3\%), glyoxylate and dicarboxylate metabolism $(1.3 \%)$, citrate cycle $(1.3 \%)$, progesterone-mediated oocyte maturation $(1.3 \%)$, Jak-STAT signaling (1.3\%), mTOR signaling $(1.3 \%)$, and toll-like receptor signaling $(1.3 \%)$ were downregulated.

\section{Validation of DEPs in SYFs of Heat-stressed TCCs}

To confirm the 2D-DIGE results, western blot and immu- nohistochemistry analyses were conducted. In the western blot analysis, the abundances of HSP25, HSP70, HSC70, and $\beta$-tubulin were consistent with the 2D-DIGE data (Fig. 4). However, immunoblot analysis showed no differences among treatments in the protein levels of HSP47 and PRDX6. In the immunohistochemical analysis, HSP70 and HSP25 were upregulated after acute heat stress, in accordance with the 2D-DIGE and western blot data. HSP70 was highly abundant in all SYF layers (Fig. 5), even the yolk-sphere layer, and HSP25 was observed mainly in the connective and theca layers (Fig. 6).

\section{Discussion}

High ambient temperatures affect reproductive and egglaying performance in chickens. Previously, we showed that the respiratory rate and body temperature of chickens increase significantly during acute heat stress and return to normal levels after recovery at $25^{\circ} \mathrm{C}$ (Luders et al., 2000; 
Table 1. Significantly DEPs in SYFs of broiler-type B strain TCC hens following acute heat stress

\begin{tabular}{|c|c|c|c|c|c|c|c|c|c|}
\hline $\begin{array}{l}\text { Spot } \\
\text { No. }\end{array}$ & $\begin{array}{l}\text { H2R0 } \\
\text { vs. } \\
\text { CTL }\end{array}$ & $\begin{array}{l}\mathrm{H} 2 \mathrm{R} 2 \\
\text { vs. } \\
\text { CTL }\end{array}$ & $\begin{array}{l}\text { H2R6 } \\
\text { vs. } \\
\text { CTL }\end{array}$ & Protein identity & Gene symbol & $\begin{array}{l}\text { GenBank } \\
\text { accession }\end{array}$ & $\begin{array}{c}\text { Theoretical } \\
\mathrm{Mr} / \mathrm{pI}\end{array}$ & $\begin{array}{l}\text { MALDI- } \\
\text { MS } \\
\text { PMF }^{\mathrm{a}}\end{array}$ & $\begin{array}{l}\text { MALDI- } \\
\text { MS/MS } \\
\text { LIFT }^{\mathrm{b}}\end{array}$ \\
\hline 12 & -1.24 & 1.22 & 1.60 & $\begin{array}{l}\text { predicted transformation/ } \\
\text { transcription domain- } \\
\text { associated protein isoform } \\
\text { X9 }\end{array}$ & TRRAP & gi|513207800 & $440291 / 9.3$ & $57 / 166(18)$ & NS \\
\hline 18 & -1.44 & 1.32 & 1.54 & vitellogenin & VTG & gi|212881 & $206862 / 9.9$ & $54 / 184(33)$ & $2(12,44)$ \\
\hline 19 & -1.43 & 1.41 & 1.58 & ovotransferrin CC type & TFEW & gi|71274077 & $79575 / 7.8$ & $24 / 175(49)$ & NS \\
\hline 22 & -1.62 & 1.14 & 1.37 & vitellogenin-1 & VTG1 & gi| 1871444 & $212608 / 9.9$ & $41 / 203(27)$ & $1(35)$ \\
\hline 26 & -1.24 & 1.35 & 1.67 & $\begin{array}{l}78 \mathrm{kDa} \text { glucose-regulated } \\
\text { protein precursor }\end{array}$ & GRP78 & gi|45382769 & $72088 / 5$ & $26 / 146(41)$ & $1(89)$ \\
\hline 32 & -1.37 & 1.51 & 1.56 & $\begin{array}{l}\text { predicted proline synthase } \\
\text { co-transcribed bacterial } \\
\text { homolog }\end{array}$ & PROSC & gi|513220600 & $34996 / 10.2$ & $16 / 184(59)$ & NS \\
\hline 41 & -1.25 & 1.41 & 1.53 & vitellogenin & VTG & gi|50582493 & $163656 / 10.1$ & $45 / 181(37)$ & $1(52)$ \\
\hline 45 & -1.69 & 1.22 & 1.40 & vitellogenin & VTG & gi|50582493 & $163656 / 10.1$ & $33 / 144(26)$ & NS \\
\hline 46 & -1.60 & 1.23 & 1.45 & vitellogenin & VTG & gi|50582493 & $163656 / 10.1$ & $29 / 154(22)$ & NS \\
\hline 51 & 1.04 & 1.34 & 1.64 & vitellogenin-1 & VTG1 & gi|1871444 & $212608 / 9.9$ & $40 / 176(26)$ & $2(67,39)$ \\
\hline 52 & -1.46 & 1.41 & 1.58 & ovotransferrin CC type & TFEW & gi|71274077 & $79575 / 7.8$ & $27 / 170(52)$ & NS \\
\hline 54 & -1.63 & 1.22 & 1.43 & cardiac muscle factor 1 & CMF1 & gi| 1621107 & $178134 / 4.8$ & $36 / 192(28)$ & NS \\
\hline 55 & -1.64 & 1.19 & 1.35 & vitellogenin I & VTG1 & gi|1871444 & $212608 / 9.9$ & NS & $1(27)$ \\
\hline 56 & -1.29 & 1.26 & 1.52 & vitellogenin & VTG & gi|50582493 & $163656 / 10.1$ & $26 / 130(22)$ & $1(24)$ \\
\hline 59 & -1.39 & 1.32 & 1.55 & $\begin{array}{l}\text { Chain A, Crystal } \\
\text { Structure Of Aluminum- } \\
\text { Bound Ovotransferrin }\end{array}$ & TFEW & gi|83754919 & $77518 / 6.8$ & $16 / 55(34)$ & NS \\
\hline 63 & -1.12 & 1.32 & 1.57 & $\begin{array}{l}\text { Chain A, Crystal } \\
\text { Structure Of Aluminum- } \\
\text { Bound Ovotransferrin }\end{array}$ & TFEW & gi|83754919 & $77518 / 6.8$ & $18 / 99(36)$ & NS \\
\hline 72 & -1.57 & 1.31 & 1.51 & $\begin{array}{l}\text { predicted uncharacterized } \\
\text { protein LOC418583 } \\
\text { isoform X5 }\end{array}$ & C1HXORF59 & gi|513163248 & $354114 / 6.5$ & $30 / 133(14)$ & NS \\
\hline 73 & -1.72 & 1.08 & 1.48 & vitellogenin I & VTG1 & gi|1871444 & $212608 / 9.9$ & $33 / 198(29)$ & $1(22)$ \\
\hline 74 & -1.60 & 1.26 & 1.50 & vitellogenin I & VTG1 & gi|1871444 & $212608 / 9.9$ & NS & $1(34)$ \\
\hline 76 & -1.75 & 1.25 & 1.44 & vitellogenin-2 precursor & VTG2 & gi|71896765 & $206732 / 9.9$ & $41 / 170(27)$ & $1(51)$ \\
\hline 77 & -1.76 & 1.23 & 1.47 & $\begin{array}{l}\text { predicted ecotropic viral } \\
\text { integration site } 5 \text { protein } \\
\text { homolog isoform X12 }\end{array}$ & EVI5 & gi|513197171 & $91114 / 5.6$ & $19 / 135(32)$ & NS \\
\hline 79 & -1.52 & 1.30 & 1.52 & vitellogenin-2 precursor & VTG2 & gi|71896765 & $206732 / 9.9$ & $39 / 205(26)$ & $1(48)$ \\
\hline 81 & -1.33 & 1.31 & 1.53 & $\begin{array}{l}\text { predicted microtubule- } \\
\text { actin cross-linking factor } \\
1 \text {, isoforms } 1 / 2 / 3 / 5 \text {-like } \\
\text { isoform X2 }\end{array}$ & LOC101748731 & gi|513221595 & $420399 / 5.2$ & $46 / 148(16)$ & $1(30)$ \\
\hline 95 & 1.64 & 1.22 & 1.34 & heat shock cognate 70 & $\mathrm{HSC} 70$ & gi|2996407 & $71011 / 5.3$ & $23 / 189(41)$ & $2(73,33)$ \\
\hline 98 & 1.59 & 1.40 & 1.55 & heat shock cognate 70 & $\mathrm{HSC} 70$ & gi|2996407 & $71011 / 5.3$ & $14 / 104(25)$ & $1(25)$ \\
\hline 102 & 1.64 & 1.12 & 1.48 & heat shock protein 70 & HSP70 & gi|421931777 & $70098 / 5.5$ & NS & $2(53,25)$ \\
\hline 104 & 1.30 & 1.73 & -1.14 & heat shock protein 70 & HSP70 & gi|421931777 & $70098 / 5.5$ & $28 / 166(41)$ & $3(38,47,58)$ \\
\hline 106 & 1.80 & 1.74 & 1.53 & heat shock protein 70 & HSP70 & gi|421931777 & $70098 / 5.5$ & $28 / 174(42)$ & $2(71,48)$ \\
\hline 107 & 1.21 & 1.52 & 1.47 & heat shock protein 70 & HSP70 & gi|421931777 & $224010 / 10.8$ & $19 / 178(43)$ & $2(50,8)$ \\
\hline 111 & 2.27 & 2.15 & 1.70 & $\begin{array}{l}\text { stress-70 protein, } \\
\text { mitochondrial precursor }\end{array}$ & HSPA9 & gi|57524986 & $73432 / 6$ & $25 / 155$ & NS \\
\hline 114 & 2.33 & 3.07 & 1.98 & heat shock protein 70 & HSP70 & gi|421931777 & $70098 / 5.5$ & $20 / 168(29)$ & $2(19,9)$ \\
\hline 130 & 4.72 & 1.12 & 2.74 & $\begin{array}{l}\text { preproalbumin (serum } \\
\text { albumin) }\end{array}$ & ALB & gi|63748 & $71868 / 5.4$ & $35 / 172(64)$ & $1(75)$ \\
\hline 136 & 1.21 & 1.81 & 1.43 & $\begin{array}{l}\text { Ig gamma chain (clone } \\
\text { 36) - chicken (fragment) }\end{array}$ & & gi| $\mid 86318$ & $54462 / 6.9$ & $9 / 79(26)$ & $2(123,70)$ \\
\hline 147 & 1.64 & 1.13 & 1.26 & $\begin{array}{l}\text { preproalbumin (serum } \\
\text { albumin) }\end{array}$ & ALB & gi|63748 & $71868 / 5.4$ & $35 / 171(61)$ & $1(38)$ \\
\hline 171 & 1.61 & 1.79 & 1.93 & $\begin{array}{l}\text { Ig gamma chain (clone } \\
\text { 36) - chicken (fragment) }\end{array}$ & & gi| 86318 & $54462 / 6.9$ & $14 / 174(32)$ & $2(109,58)$ \\
\hline
\end{tabular}


Table 1. Significantly DEPs in SYFs of broiler-type B strain TCC hens following acute heat stress (continued)

\begin{tabular}{|c|c|c|c|c|c|c|c|c|c|}
\hline $\begin{array}{l}\text { Spot } \\
\text { No. }\end{array}$ & $\begin{array}{l}\text { H2R0 } \\
\text { vs. } \\
\text { CTL }\end{array}$ & $\begin{array}{l}\mathrm{H} 2 \mathrm{R} 2 \\
\text { vs. } \\
\text { CTL }\end{array}$ & $\begin{array}{l}\text { H2R6 } \\
\text { vs. } \\
\text { CTL }\end{array}$ & Protein identity & Gene symbol & $\begin{array}{l}\text { GenBank } \\
\text { accession }\end{array}$ & $\begin{array}{c}\text { Theoretical } \\
\mathrm{Mr} / \mathrm{pI}\end{array}$ & $\begin{array}{l}\text { MALDI- } \\
\text { MS } \\
\text { PMF }^{\mathrm{a}}\end{array}$ & $\begin{array}{l}\text { MALDI- } \\
\text { MS/MS } \\
\text { LIFT }^{\mathrm{b}}\end{array}$ \\
\hline 193 & -1.06 & 1.59 & 1.39 & $\begin{array}{l}\text { Ig gamma chain (clone } \\
\text { 36) - chicken (fragment) }\end{array}$ & & gi| $\mid 86318$ & $54462 / 6.9$ & $13 / 170(35)$ & $2(19,118)$ \\
\hline 197 & 1.57 & 1.28 & 1.57 & apolipoprotein B & APOB & gi|102221132 & $524519 / 9$ & $67 / 171(18)$ & NS \\
\hline 226 & 1.51 & 1.19 & -1.11 & $\begin{array}{l}\text { predicted cytoskeleton- } \\
\text { associated protein } 4, \\
\text { partial }\end{array}$ & CKAP4 & gi|513159594 & $54564 / 4.8$ & $19 / 156(43)$ & $1(43)$ \\
\hline 230 & 1.07 & 1.03 & 1.54 & apolipoprotein B & APOB & gi|102221132 & $524519 / 9$ & NS & $1(31)$ \\
\hline 237 & 1.40 & 1.32 & 1.58 & $\begin{array}{l}\text { predicted stress-induced- } \\
\text { phosphoprotein 1-like }\end{array}$ & & & $34241 / 5.4$ & NS & $\begin{array}{l}3(33,123, \\
112)\end{array}$ \\
\hline 241 & 1.16 & 1.49 & 1.71 & apolipoprotein B & АРOB & gi|102221132 & $524519 / 9$ & NS & $1(14)$ \\
\hline 278 & -1.03 & -1.54 & -1.45 & $\begin{array}{l}\text { prolyl-4-hydroxylase } \\
\text { (AA } 5-494 \text { ) }\end{array}$ & ARHGAP39 & & $55174 / 4.5$ & NS & $2(99,155)$ \\
\hline 338 & 1.28 & 1.23 & 1.59 & $\begin{array}{l}\text { predicted IQ motif and } \\
\text { ubiquitin domain } \\
\text { containing isoform X3 }\end{array}$ & IQUB & gi|513158028 & $81804 / 7.3$ & $17 / 133(30)$ & NS \\
\hline 347 & 1.02 & -1.57 & -1.53 & tubulin beta- 7 chain & TUBB & gi|45384338 & $50095 / 4.6$ & $25 / 178(60)$ & $\begin{array}{l}4(43,27,28, \\
144)\end{array}$ \\
\hline 360 & -1.01 & -1.51 & -1.16 & Vimentin & VIM & gi|114326309 & $53167 / 4.9$ & $20 / 54(44)$ & NS \\
\hline 362 & -1.27 & 1.13 & 1.54 & apolipoprotein B & APOB & gi|102221132 & $524519 / 9$ & $43 / 84(10)$ & $2(45,9)$ \\
\hline 372 & -1.27 & 1.13 & 1.58 & apolipoprotein B & APOB & gi|102221132 & $524519 / 9$ & $36 / 69(8)$ & $1(52)$ \\
\hline 382 & 1.05 & 1.22 & 1.53 & vitellogenin I & VTG1 & gi|1871444 & $212608 / 9.9$ & NS & $2(44,47)$ \\
\hline 383 & 1.50 & 1.69 & 1.46 & otokeratin & KRT & gi $\mid 3746660$ & $53770 / 5.9$ & NS & $1(36)$ \\
\hline 392 & 1.14 & -1.55 & -1.67 & cytokeratin otokeratin & KRT & gi|34922442 & $53770 / 5.9$ & $26 / 118(50)$ & $1(62)$ \\
\hline 393 & -1.08 & -1.37 & -1.62 & tubulin beta- 7 chain & TUBB & gi|45384338 & $50095 / 4.6$ & $25 / 177(56)$ & $2(41,147)$ \\
\hline 394 & 1.33 & 1.18 & 1.62 & alpha-actin & ASMA & gi|211205 & $42367 / 5.1$ & $7 / 43(24)$ & $2(16,102)$ \\
\hline 398 & -1.08 & -1.41 & -1.51 & desmin & DES & gi|2959450 & $51689 / 5.2$ & $26 / 120(50)$ & $2(49,105)$ \\
\hline 399 & -1.51 & -1.22 & -1.21 & $\begin{array}{l}\text { predicted ATP synthase } \\
\text { subunit alpha, } \\
\text { mitochondrial isoform X2 }\end{array}$ & ATP5A1W & gi|363745506 & $60162 /$ & $16 / 118(37)$ & $1(36)$ \\
\hline 405 & 1.28 & 1.41 & 1.56 & desmin & DES & gi|2959450 & $51689 / 5.2$ & $26 / 109(54)$ & $2(31,71)$ \\
\hline 434 & 1.09 & 1.10 & 1.62 & alpha-enolase & ENO1 & gi|1706653 & $47617 / 6.2$ & $18 / 128(49)$ & $\begin{array}{l}3(70,51, \\
156)\end{array}$ \\
\hline 440 & 1.06 & 1.54 & 1.31 & $\begin{array}{l}\text { chain } \mathrm{A} \text {, chicken } \\
\text { cytochrome } \mathrm{Bc} 1 \text { complex } \\
\text { inhibited by an iodinated } \\
\text { analog of the polyketide } \\
\text { crocacin-d }\end{array}$ & & gi|196049775 & $49981 / 5.9$ & $20 / 148(53)$ & $2(83,118)$ \\
\hline 452 & 1.16 & 1.61 & 1.45 & vitellogenin I & VTGI & gi|1871444 & $212608 / 9.9$ & NS & $2(1,44)$ \\
\hline 454 & 1.19 & 1.76 & 1.55 & vitellogenin I & VTGI & gi| 1871444 & $212608 / 9.9$ & $21 / 100$ & $2(37,43)$ \\
\hline 458 & 1.23 & 1.64 & 1.32 & heat shock protein 47 & HSP47 & gi|63511 & $45711 / 9.2$ & $15 / 49(42)$ & NS \\
\hline 472 & -1.17 & -1.50 & -1.85 & beta-actin & АCTB & gi|211237 & $41921 / 5.2$ & $11 / 84(41)$ & $2(57,106)$ \\
\hline 476 & -1.18 & -1.12 & -1.60 & vimentin & VIM & gi|114326309 & $53167 / 4.9$ & $27 / 96(51)$ & $2(29,66)$ \\
\hline 511 & 1.65 & -1.09 & -1.30 & vitellogenin I & VTGI & gi|1871444 & $212608 / 9.9$ & 29/134 (24) & $2(48,26)$ \\
\hline 513 & 1.24 & 1.00 & 1.56 & $\begin{array}{l}\text { zona pellucida } \\
\text { glycoprotein } \mathrm{C}\end{array}$ & $\mathrm{ZPC}$ & gi|194725155 & $47649 / 5.9$ & $8 / 68(33)$ & $1(53)$ \\
\hline 516 & -1.03 & 1.23 & 1.52 & beta-actin & & & $42151 / 5.2$ & NS & $1(38)$ \\
\hline 518 & -1.13 & -1.46 & -1.62 & SPARC precursor & SPARC & gi|45383337 & $34894 / 4.6$ & $10 / 134(33)$ & $2(59,75)$ \\
\hline 538 & 2.65 & 1.45 & -1.11 & vitellogenin I & VTGI & gi|1871444 & $212608 / 9.9$ & 27/110 (17) & $2(79,61)$ \\
\hline 554 & 1.64 & 1.06 & -1.16 & gamma-actin & ACTG1 & gi|82197919 & $42108 / 5.2$ & $22 / 136(65)$ & $2(50,114)$ \\
\hline 555 & 2.08 & 1.18 & -1.06 & NS & & & & & \\
\hline 584 & 1.95 & 1.52 & 1.32 & $\begin{array}{l}\text { NADH dehydrogenase } \\
\text { [ubiquinone] } 1 \text { alpha } \\
\text { subcomplex subunit } 10 \text {, } \\
\text { mitochondrial }\end{array}$ & NDUFA10 & gi|71895153 & $41633 / 6.2$ & $9 / 60(31)$ & $1(64)$ \\
\hline
\end{tabular}


Table 1. Significantly DEPs in SYFs of broiler-type B strain TCC hens following acute heat stress (continued)

\begin{tabular}{|c|c|c|c|c|c|c|c|c|c|}
\hline $\begin{array}{l}\text { Spot } \\
\text { No. }\end{array}$ & $\begin{array}{l}\text { H2R0 } \\
\text { vs. } \\
\text { CTL }\end{array}$ & $\begin{array}{l}\mathrm{H} 2 \mathrm{R} 2 \\
\text { vs. } \\
\text { CTL }\end{array}$ & $\begin{array}{l}\text { H2R6 } \\
\text { vs. } \\
\text { CTL }\end{array}$ & Protein identity & Gene symbol & $\begin{array}{l}\text { GenBank } \\
\text { accession }\end{array}$ & $\begin{array}{c}\text { Theoretical } \\
\mathrm{Mr} / \mathrm{pI}\end{array}$ & $\begin{array}{l}\text { MALDI- } \\
\text { MS } \\
\text { PMF }^{\mathrm{a}}\end{array}$ & $\begin{array}{l}\text { MALDI- } \\
\text { MS/MS } \\
\text { LIFT }^{b}\end{array}$ \\
\hline 622 & 1.63 & 1.24 & 1.08 & $\begin{array}{l}\text { predicted T-cell- } \\
\text { interacting, activating } \\
\text { receptor on myeloid cells } \\
\text { protein 1-like, partial }\end{array}$ & LOC 101747418 & gi|513239402 & $22226 / 9.7$ & $5 / 26(25)$ & NS \\
\hline 629 & 2.23 & 1.38 & -1.06 & vitellogenin & VTG & gi|212881 & $206732 / 9.9$ & NS & $1(54)$ \\
\hline 630 & 2.49 & 1.37 & 1.08 & vitellogenin & VTG & gi|212881 & $206862 / 9.9$ & NS & $2(65,142)$ \\
\hline 638 & 1.69 & 1.32 & 1.09 & $\begin{array}{l}\text { predicted kinesin family } \\
\text { member } 27 \text { isoform } \mathrm{X} 4\end{array}$ & KIF27 & gi|513230948 & $161658 / 6.5$ & $27 / 122(25)$ & NS \\
\hline 641 & 2.04 & 1.18 & -1.07 & apolipoprotein A-I & APOA1 & gi|211148 & $30661 / 5.5$ & $7 / 103(27)$ & NS \\
\hline 652 & -1.14 & -1.77 & -1.14 & NS & & & & & \\
\hline 684 & 1.55 & 1.22 & 1.05 & $\begin{array}{l}\text { predicted leucine-rich } \\
\text { repeat serine/threonine- } \\
\text { protein kinase 2-like }\end{array}$ & LOC101752326 & gi|513240589 & $15182 / 7.8$ & $2 / 47(22)$ & NS \\
\hline 693 & -1.37 & -2.05 & -1.29 & $\begin{array}{l}\text { calcium-activated } \\
\text { potassium channel } \\
\text { variant } \mathrm{C} 4 \mathrm{p} 6-\mathrm{AB} 2\end{array}$ & KCNMAL & gi|289688683 & $45224 / 9.1$ & 4/53 (17) & NS \\
\hline 712 & -1.07 & -1.51 & -1.54 & $\begin{array}{l}\text { predicted nucleolar } \\
\text { transcription factor 1-like }\end{array}$ & & gi|363746001 & $13574 / 6.4$ & $6 / 45(48)$ & NS \\
\hline 720 & 1.05 & -1.58 & -1.25 & $\begin{array}{l}\text { alpha-tropomyosin } \\
\text { (partial), partial }\end{array}$ & TPM1 & gi|212815 & $30102 / 4.5$ & $5 / 6(17)$ & $1(65)$ \\
\hline 763 & 1.65 & 1.24 & 1.06 & $\begin{array}{l}\text { RecName: Full=Serum } \\
\text { albumin; AltName: } \\
\text { Full=Alpha-livetin; Al }\end{array}$ & ALB & gi|113575 & $71868 / 5.4$ & 29/157 (38) & NS \\
\hline 792 & 1.01 & -1.75 & -1.49 & alpha-tropomyosin & TPM1 & gi|211109 & $32940 / 4.6$ & 23/107 (59) & $3(85,80,40)$ \\
\hline 799 & 1.25 & 1.79 & 1.07 & $\begin{array}{l}\text { RNA-binding protein } \\
\mathrm{HuC}\end{array}$ & HUC & gi|45382281 & $39359 / 10$ & $6 / 54(23)$ & NS \\
\hline 811 & 1.10 & 1.20 & 1.54 & $\begin{array}{l}\text { protein disulfide- } \\
\text { isomerase A4 }\end{array}$ & PDIA4 & gi $\mid 57530768$ & $71285 / 4.8$ & $10 / 48(20)$ & NS \\
\hline 814 & 1.08 & 1.43 & 1.54 & $\begin{array}{l}\text { Ig gamma chain (clone } \\
\text { 36) - chicken (fragment) }\end{array}$ & & gi| 86318 & $54462 / 6.9$ & $6 / 45917)$ & $2(15,86)$ \\
\hline 854 & -1.47 & -2.01 & -1.56 & $\begin{array}{l}\text { predicted protein- } \\
\text { methionine sulfoxide } \\
\text { oxidase MICAL3 isoform } \\
\text { X5 }\end{array}$ & MICAL3 & gi|513160265 & $238943 / 5.3$ & $20 / 59(12)$ & NS \\
\hline 862 & 1.34 & 1.70 & 2.00 & vitellogenin & VTG & gi|212881 & $206862 / 9.9$ & NS & $2(90,76)$ \\
\hline 875 & -1.18 & 1.80 & 1.27 & $\begin{array}{l}\text { predicted rab-interacting } \\
\text { lysosomal protein isoform } \\
\mathrm{X} 2\end{array}$ & RILP & gi|513215705 & $45485 / 4.9$ & $12 / 85(41)$ & NS \\
\hline 904 & -1.87 & -11.52 & -3.01 & $\begin{array}{l}\text { predicted uncharacterized } \\
\text { protein LOC101750595 } \\
\text { isoform X2 }\end{array}$ & LOC101750595 & gi|513192887 & $27136 / 10.9$ & $7 / 112(45)$ & NS \\
\hline 908 & -1.33 & -2.07 & -1.89 & $\begin{array}{l}\text { predicted guanylate } \\
\text { cyclase soluble subunit } \\
\text { beta- } 2 \text { isoform X3 }\end{array}$ & GUCY1B2 & gi|513199296 & $89483 / 6.9$ & 17/111 (27) & NS \\
\hline 935 & -1.97 & -4.54 & -2.45 & prohibitin & PHB & gi|88909244 & $29935 / 5.5$ & $10 / 126(55)$ & $\begin{array}{l}4(50,118 \\
149,25)\end{array}$ \\
\hline 992 & -1.63 & -2.06 & -1.49 & $\begin{array}{l}\text { predicted ATP-binding } \\
\text { cassette sub-family A } \\
\text { member } 3 \text { isoform }\end{array}$ & $\mathrm{ABCA} 3$ & gi| 85700402 & $200319 / 6.9$ & NS & $1(11)$ \\
\hline 996 & 1.45 & 1.14 & 1.66 & peroxiredoxin-6 & PRDX6 & gi|86129578 & $25075 / 5.6$ & $12 / 130(58)$ & $2(78,92)$ \\
\hline 1001 & 1.54 & 1.47 & 1.43 & $\begin{array}{l}\text { phosphoglycerate } \\
\text { mutase } 1\end{array}$ & PGAM1 & gi|71895985 & $29051 / 7.8$ & $11 / 86(51)$ & $2(73,80)$ \\
\hline 1022 & 1.38 & 1.04 & 1.69 & $\begin{array}{l}\text { ubiquitin carboxyl- } \\
\text { terminal hydrolase } \\
\text { isozyme L1 }\end{array}$ & UCHL1 & gi|122692295 & $25380 / 5.7$ & $8 / 77(48)$ & $\begin{array}{l}3(122,116, \\
16)\end{array}$ \\
\hline 1039 & 2.27 & 1.38 & 1.20 & B-G antigen, partial & BG1 & gi|211252 & $19869 / 6.8$ & $4 / 62(37)$ & NS \\
\hline
\end{tabular}


Table 1. Significantly DEPs in SYFs of broiler-type B strain TCC hens following acute heat stress (continued)

\begin{tabular}{|c|c|c|c|c|c|c|c|c|c|}
\hline $\begin{array}{l}\text { Spot } \\
\text { No. }\end{array}$ & $\begin{array}{l}\text { H2R0 } \\
\text { vs. } \\
\text { CTL }\end{array}$ & $\begin{array}{l}\mathrm{H} 2 \mathrm{R} 2 \\
\text { vs. } \\
\text { CTL }\end{array}$ & $\begin{array}{l}\text { H2R6 } \\
\text { vs. } \\
\text { CTL }\end{array}$ & Protein identity & Gene symbol & $\begin{array}{l}\text { GenBank } \\
\text { accession }\end{array}$ & $\begin{array}{c}\text { Theoretical } \\
\mathrm{Mr} / \mathrm{pI}\end{array}$ & $\begin{array}{l}\text { MALDI- } \\
\text { MS } \\
\text { PMF }^{\mathrm{a}}\end{array}$ & $\begin{array}{l}\text { MALDI- } \\
\text { MS/MS } \\
\text { LIFT }^{b}\end{array}$ \\
\hline 1046 & 1.60 & 1.30 & 1.14 & $\begin{array}{l}\text { synaptosomal-associated } \\
\text { protein } 23\end{array}$ & SNAP23 & gi|313851076 & $23874 / 4.8$ & $10 / 20(47)$ & $1(33)$ \\
\hline 1048 & 1.76 & 1.16 & 1.14 & $\begin{array}{l}\text { preproalbumin (serum } \\
\text { albumin) }\end{array}$ & & & $71868 / 5.4$ & NS & $1(44)$ \\
\hline 1061 & 1.12 & 1.47 & 1.70 & $\begin{array}{l}\text { pseudouridylate synthase } \\
7 \text { homolog }\end{array}$ & PUS7 & gi|313747563 & $74231 / 6.2$ & $11 / 47(23)$ & NS \\
\hline 1075 & 4.96 & 6.56 & 2.45 & heat shock protein 25 & HSP25 & gi|50838655 & $19086 / 6.4$ & NS & $2(85,68)$ \\
\hline 1076 & 1.46 & 1.58 & 1.11 & cathepsin B & CTSB & gi|603203 & $38475 / 5.7$ & $10 / 116(32)$ & $2(80,107)$ \\
\hline 1077 & 1.18 & 2.58 & 2.40 & heat shock protein 25 & HSP25 & gi|50838655 & $19086 / 6.4$ & NS & $2(78,78)$ \\
\hline 1093 & 1.89 & 1.95 & 1.17 & heat shock protein 25 & HSP25 & gi|50838655 & $19086 / 6.4$ & NS & $2(20,60)$ \\
\hline 1206 & 1.88 & 1.01 & 1.05 & $\begin{array}{l}\text { mitochondrial import } \\
\text { inner membrane } \\
\text { translocase subunit Tim9 }\end{array}$ & TIMM9 & gi| 403048737 & $10704 / 7.7$ & $7 / 119(83)$ & NS \\
\hline 1227 & 2.05 & 1.07 & 1.10 & $\begin{array}{l}\text { ectodermal neural-cortex } \\
3 \text {, partial }\end{array}$ & ENC3 & gi|542132081 & $37191 / 6.3$ & 11/101 (39) & NS \\
\hline 1258 & 1.81 & -1.22 & -1.56 & $\begin{array}{l}\text { predicted kinesin light } \\
\text { chain } 4 \text { isoform } \mathrm{X} 8\end{array}$ & KLC4 & gi|513174135 & $61647 / 6.1$ & $6 / 50(18)$ & NS \\
\hline 1418 & 1.51 & -1.26 & 1.31 & $\begin{array}{l}\text { predicted V-set and } \\
\text { transmembrane domain- } \\
\text { containing protein }\end{array}$ & VSTM2A & gi|513171223 & $23766 / 7.7$ & 4/18 (26) & NS \\
\hline 1489 & 1.05 & 1.70 & 1.55 & $\begin{array}{l}\text { predicted WD repeat- } \\
\text { containing protein } 20 \\
\text { isoform X8 }\end{array}$ & WDR20 & gi|513189205 & $11718 / 10.1$ & $5 / 29(35)$ & $2(87,93)$ \\
\hline 1494 & -1.59 & 1.14 & 1.16 & $\begin{array}{l}\text { cytoplasmic aconitate } \\
\text { hydratase }\end{array}$ & $\mathrm{ACO} 1$ & gi|72535134 & $98639 / 7.2$ & 17/111 (25) & NS \\
\hline 1532 & 1.67 & 1.18 & 1.22 & $\begin{array}{l}\text { predicted high affinity } \\
\text { cGMP-specific } 3^{\prime}, 5^{\prime}- \\
\text { cyclic phosphodiesterase } \\
9 \mathrm{~A} \text { isoform X2 }\end{array}$ & PDE9A & gi|363728761 & $53631 / 5.6$ & $8 / 33(16)$ & NS \\
\hline 1617 & -1.18 & -1.34 & -1.86 & Vimentin & VIM & gi|114326309 & $53167 / 4.9$ & $26 / 111(41)$ & $2(5,63)$ \\
\hline 1621 & 1.83 & 1.37 & 1.09 & $\begin{array}{l}\text { ATP synthase subunit } \\
\text { beta, mitochondrial } \\
\text { precursor }\end{array}$ & АТР5B & gi|448261627 & $56650 / 5.5$ & $31 / 131(66)$ & $2(55,107)$ \\
\hline 1626 & -1.09 & -1.72 & -1.65 & vimentin & VIM & gi|114326309 & $53167 / 4.9$ & $32 / 121(52)$ & $2(33,60)$ \\
\hline 1632 & 1.55 & -1.02 & -1.16 & vitellogenin & VTG & gi|50582493 & $163656 / 10.1$ & NS & $2(82,167)$ \\
\hline 1634 & -1.75 & -3.26 & -1.99 & $\begin{array}{l}\text { phosphatidylinositol-4,5- } \\
\text { bisphosphate 3-kinase } \\
\text { catalytic subunit alpha } \\
\text { isoform }\end{array}$ & PIK3CA & gi|52138709 & $126089 / 6.9$ & $16 / 96(21)$ & $1(18)$ \\
\hline 1648 & 1.20 & 1.20 & 1.63 & $\begin{array}{l}\text { predicted ATP synthase } \\
\text { subunit alpha, } \\
\text { mitochondrial isoform X2 }\end{array}$ & ATP5A1W & gi|363745506 & $60162 / 9.5$ & $25 / 187(50)$ & $1(109)$ \\
\hline 1649 & 1.65 & 1.16 & -1.07 & vitellogenin & VTG & gi|50582493 & $163656 / 10.1$ & NS & $1(65)$ \\
\hline 1663 & 1.11 & 1.23 & 1.56 & $\begin{array}{l}\text { Ig gamma chain } \\
\text { (clone } 36) \text { - chicken } \\
\text { (fragment) }\end{array}$ & & gi|86318 & $54462 / 6.9$ & $11 / 128(26)$ & $2(138,45)$ \\
\hline 1683 & 1.05 & 1.07 & 1.61 & $\begin{array}{l}\text { predicted PDZ and LIM } \\
\text { domain protein } 1 \text { isoform } \\
\mathrm{X} 4\end{array}$ & PDLIM1 & gi|513191054 & $36094 / 7$ & $17 / 171$ & $3(52,58,87)$ \\
\hline
\end{tabular}

Abbreviations: CTL, control group; H2R0, H2R2, H2R6, heat stress for $2 \mathrm{~h}$ and recovery for 0,2 , or $6 \mathrm{~h}$; LIFT, laser-induced forward transfer; MALDI-MS, matrix-assisted laser desorption/ionization mass spectrometer; NS, no significant match; PMF, peptide mass fingerprinting.

${ }^{\mathrm{a}}$ The column refers to the results of the MALDI-MS PMF analysis, i.e., the number of assigned peptides and percent sequence coverage (in parentheses).

${ }^{\mathrm{b}}$ The column refers to the results of the MALDI-MS/MS analysis, i.e., to the number and Mascot scores (in parentheses) of assigned peptides. 


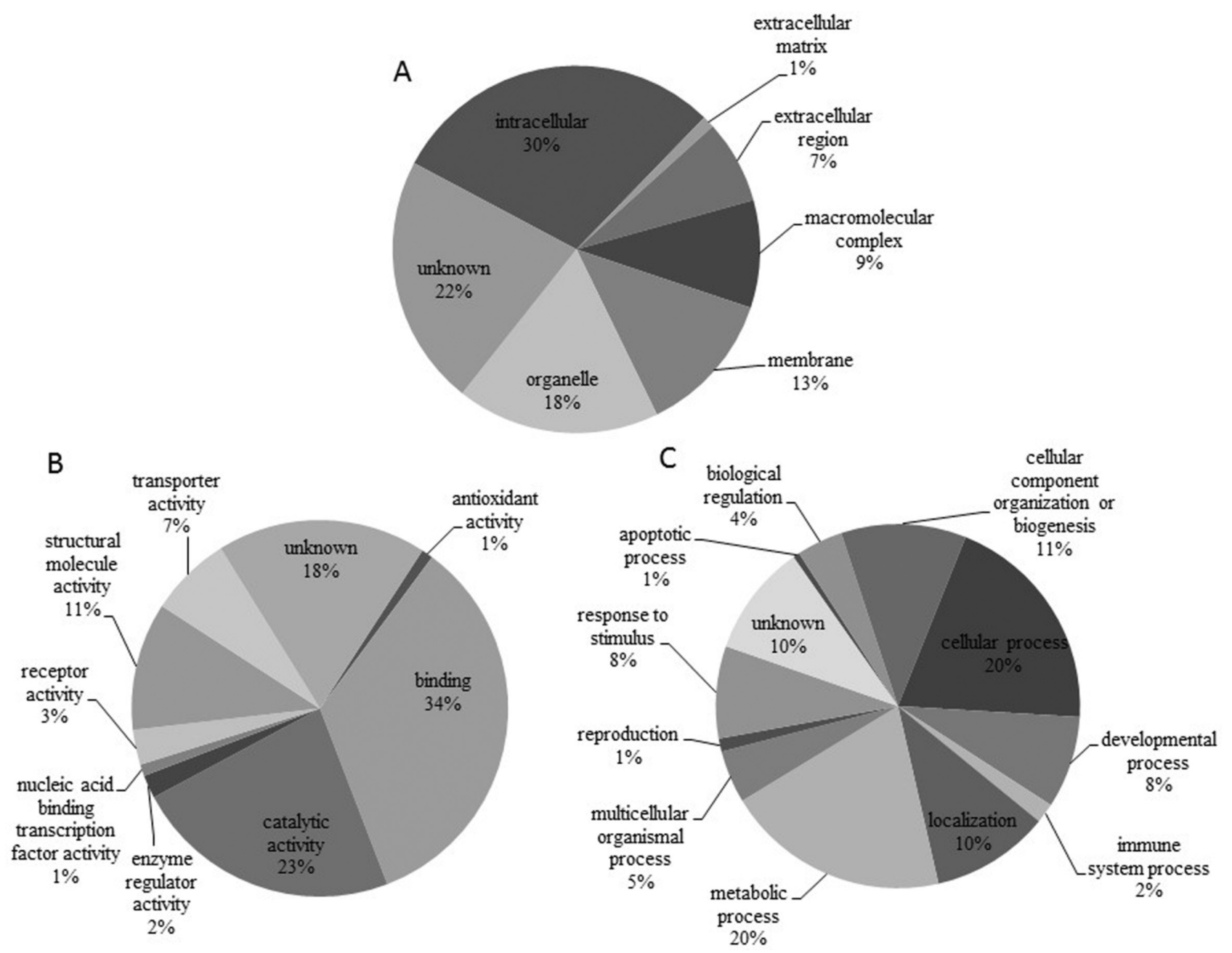

Fig. 3. Pie charts showing classification of significantly DEPs in SYFs of broiler-type B strain TCCs exposed to $38^{\circ} \mathrm{C}$ acute heat stress for $2 \mathrm{~h}$, with recovery for 0,2 , or $6 \mathrm{~h}$, by cellular components (A), molecular functions (B), and biological processes (C).

Cheng et al., 2015). In the present study, we used a proteomic approach to investigate protein abundances in the SYFs of broiler-type B strain TCCs in response to acute heat stress. In total, 76 distinct proteins were significantly differentially expressed after a 2-h exposure to heat, most of which are involved in metabolic processes, cellular processes, cellular component organization or biogenesis, developmental processes, or responses to stress cues.

\section{Regulation of HSPs and Anti-oxidative Defense of SYFs After Acute Heat Stress}

Heat stress causes apoptosis and follicular atresia in ovaries (Li, 1987; Lin et al., 2012). HSPs protect cells from damage and prevent aggregation of misfolded proteins in response to a variety of stress cues ( $\mathrm{Li}, 1987$; Johnston et al., 1998; Wang et al., 2014; Cheng et al., 2015). Accordingly, the abundances of HSP25, HSP47, HSP70, HSC70, HSPA9, and GRP78 increased as a protective mechanism in the SYFs of hens in response to acute heat stress (Table 1). Consistent with our genomic analysis (Cheng et al., 2015), the upregulation of HSPs, particularly, HSP25, points to the existence of several protective mechanisms, including anti-apoptotic/ necroptotic activity, anti-ER stress effects, and pro-autophagic activity for aggregated protein clearance (Luders et al., 2000; Liu et al., 2010; Delavallee et al., 2011). Li et al. (2016) demonstrated increased abundance of HSP70 in association with apoptotic granulosa cells and follicular atresia in mouse ovaries after chronic heat stress. In the present study, TUNEL-positive cells were observed in the SYFs of heat-stressed hens; however, there were no differences among the groups. The fact that SYFs maintained normal phenotype after acute heat stress, even after $6 \mathrm{~h}$ of recovery, suggests that the heat stress was not sufficient to induce atresia via apoptosis or that the observation time was not sufficiently long to observe atresia. In a study by Beraldo et 
Table 2. Pathways related to proteins significantly differentially expressed in chicken small yellow follicles after acute heat stress

\begin{tabular}{|c|c|}
\hline KEGG pathway & Related proteins and their abundance in chicken SYF after heat stress ${ }^{a}$ \\
\hline $\mathrm{ABC}$ transporters & ATP-binding cassette sub-family A member 3 isoform $(\downarrow)$ \\
\hline Biosynthesis of amino acids & $\begin{array}{l}\text { cytoplasmic aconitate hydratase }(\downarrow), \text { PDZ and LIM domain protein } 1 \text { isoform X4 ( } \uparrow) \text {, } \\
\text { alpha-enolase }(\uparrow)\end{array}$ \\
\hline Carbon metabolism & $\begin{array}{l}\text { cytoplasmic aconitate hydratase }(\downarrow), \mathrm{PDZ} \text { and LIM domain protein } 1 \text { isoform X4 ( } \uparrow) \text {, } \\
\text { alpha-enolase }(\uparrow)\end{array}$ \\
\hline Ether lipid metabolism & alpha-actin $(\uparrow)$ \\
\hline $\begin{array}{l}\text { Glycine, serine and threonine } \\
\text { metabolism }\end{array}$ & PDZ and LIM domain protein 1 isoform $\mathrm{X} 4(\uparrow)$ \\
\hline $\begin{array}{l}\text { Glyoxylate and dicarboxylate } \\
\text { metabolism }\end{array}$ & cytoplasmic aconitate hydratase $(\downarrow)$ \\
\hline Citrate cycle (TCA cycle) & cytoplasmic aconitate hydratase $(\downarrow)$ \\
\hline Endocytosis & alpha-actin $(\uparrow)$, heat shock cognate $70(\uparrow)$, heat shock protein $70(\uparrow)$ \\
\hline Glycolysis / Gluconeogenesis & PDZ and LIM domain protein $1(\uparrow)$, Alpha-enolase $(\uparrow)$ \\
\hline Oxidative phosphorylation & $\begin{array}{l}\text { ATP synthase subunit alpha, mitochondrial isoform X2 }(\downarrow,-, \uparrow) \text {, ATP synthase subunit beta }(\uparrow) \text {, } \\
\text { protein-methionine sulfoxide oxidase MICAL3 isoform X5 }(\downarrow)\end{array}$ \\
\hline $\begin{array}{l}\text { Progesterone-mediated oocyte } \\
\text { maturation }\end{array}$ & preproalbumin $(\downarrow)$ \\
\hline $\begin{array}{l}\text { Protein processing in } \\
\text { endoplasmic reticulum }\end{array}$ & $\begin{array}{l}\text { cytoskeleton-associated protein } 4(\uparrow) \text {, high affinity cGMP-specific } 3^{\prime}, 5^{\prime} \text {-cyclic phosphodiesterase } \\
9 \mathrm{~A} \text { isoform } \mathrm{X} 2(\uparrow) \text {, heat shock protein } 70(\uparrow) \text {, heat shock protein } 47(\uparrow)\end{array}$ \\
\hline RNA degradation & alpha-enolase $(\uparrow)$ \\
\hline Gap junction or tight junction & $\begin{array}{l}\text { transformation/transcription domain-associated protein isoform X9 }(\uparrow) \text {, guanylate cyclase soluble } \\
\text { subunit beta-2 isoform X3 }(\downarrow) \text {, beta-actin }(\downarrow) \text {, cytoskeleton-associated protein } 4(\uparrow)\end{array}$ \\
\hline Regulation of actin cytoskeleton & beta-actin $(\downarrow)$, gamma-actin $(\uparrow)$, prohibitin $(\downarrow)$ \\
\hline Metabolic pathways & $\begin{array}{l}\text { cytoplasmic aconitate hydratase }(\downarrow) \text {, ATP synthase subunit beta }(\uparrow) \text {, PDZ and LIM domain protein } \\
1 \text { isoform X4 }(\uparrow) \text {, alpha-enolase }(\uparrow) \text {, ATP synthase subunit alpha, mitochondrial isoform X2 }(\downarrow,- \text {, } \\
\uparrow) \text {, protein-methionine sulfoxide oxidase MICAL3 isoform X5 }(\downarrow)\end{array}$ \\
\hline \multicolumn{2}{|l|}{ Specific signaling pathway } \\
\hline Adipocytokine signaling pathway & alpha-actin $(\uparrow)$ \\
\hline Calcium signaling pathway & alpha-actin $(\uparrow)$ \\
\hline Fanconi anemia pathway & preproalbumin $(\uparrow)$ \\
\hline Jak-STAT signaling pathway & prohibitin $(\downarrow)$ \\
\hline MAPK signaling pathway & heat shock protein $70(\uparrow)$ \\
\hline mTOR signaling pathway & prohibitin $(\downarrow)$ \\
\hline PPAR signaling pathway & apolipoprotein A-I ( $\uparrow)$ \\
\hline Toll-like receptor signaling pathway & prohibitin $(\downarrow)$ \\
\hline
\end{tabular}

a $\uparrow$, increased after heat stress; -, no significant change after heat stress; $\downarrow$, decreased after heat stress

al. (2015), STIP1, a co-chaperone of HSP70/HSP90, was upregulated in SYFs after acute heat stress. GRP78 (also known as HSPA5), an endoplasmic reticulum marker, was upregulated in goat granulosa cells during follicular atresia (Lin et al., 2012). The collagen-specific molecular chaperone HSP47 (Taguchi and Razzaque, 2007) was upregulated in SYFs of both broiler-type B strain (Table 1) and layer-type L2 strain TCCs (Cheng et al., unpublished). These results suggest that heat stress activates a cell death program that in turn induces a variety of stress-related proteins as a protective response to maintain protein functionality for normal cell function and integrity.

Acute and chronic heat stress can lead to oxidative stress in poultry and to the production of lipid peroxidation products (aldehydes, hydrocarbons, and isoprostanes) and plasma and tissue protein carbonyls (Akbarian et al., 2016). The increased oxidative stress is attributed to increased electron leakage leading to ROS generation through accelerated mitochondrial metabolic processes to meet the cellular energy demand for heat dissipation. Acute heat stress can result in the downregulation of uncoupling protein, further exacerbating the oxidative stress and thus, leading to mitochondrial dysfunction and tissue damage. Typically, heat stress depletes the cellular glutathione reservoir and tends to upregulate antioxidant enzyme activities. The upregulation of PRDX enzymes in response to oxidative insults has been demonstrated in various cell lines (Rhee et al., 2012). In SYFs of layer-type TCCs, we observed upregulation of PRDX1, 2, and 4 after acute heat stress (Cheng et al., unpublished). PRDX converts hydrogen peroxide into water. PRDX6 specifically binds to peroxidized phospholipids in the cell membranes following oxidative stress, and its abundance is associated with a decrease (compatible with repair) of phospholipid hydroperoxides (Li et al., 2015). The PRDX 

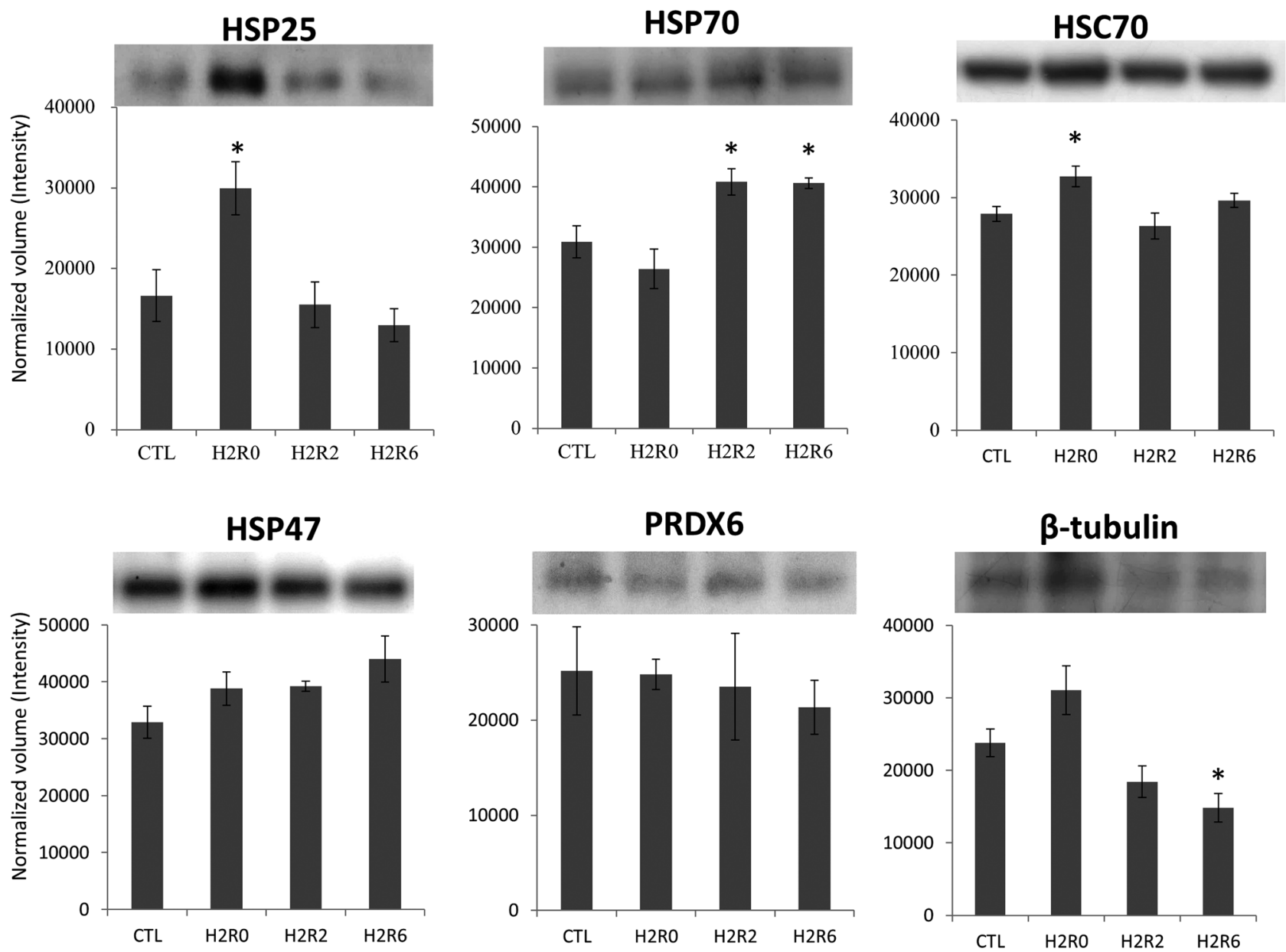

Fig. 4. Western blot of significantly DEPs in SYFs of broiler-type B strain TCCs after acute heat stress. Protein abundance was normalized to the density of total protein with Image Lab software (Version 5.2.1, Bio-Rad). HSP, heat-shock protein; HSC70, heat shock cognate 70; PRDX6, peroxiredoxin-6; $\beta$-tubulin, beta tubulin. ${ }^{*} P<0.05$.

system might thus act as a crucial antioxidative defense to prevent peroxidation of membrane lipids in the SYFs of hens after acute heat stress.

\section{Heat Stress Alters Egg Yolk Precursors and Cytoskeleton Proteins in SYFs}

Egg yolk proteins such as vitellogenin (VTG) and apolipoproteins (APOs) are synthesized in the liver by estrogen induction during the laying stage (Deeley et al., 1975; Schneider, 1992). Previously, we observed increased VTG2 mRNA expression in the SYFs of broiler-type TCCs after acute heat stress (Cheng et al., 2015). In the present study, the abundances of APOA1, APOB, and VTGs were dynamically regulated after acute heat stress in the SYFs of broiler-type B strain TCCs (Table 1). VTGs are the main source of the amino acids incorporated into structural and non-structural proteins translated by the embryo (Finn, 2007) and act as an immune effector to protect the embryo from bacteria and viruses (Sun and Zhang, 2015). Downregu- lation of VTGs in SYFs after acute heat stress and upregulation after $6 \mathrm{~h}$ of recovery (Table 1) may suggest that the loss of egg yolk might recover after heat stress. Highdensity lipoprotein and its major protein component, APOA1, function to remove excessive cholesterol from peripheral cells and to deliver it to the liver (Davidson et al., 1996). APOB mainly delivers cargo lipids of hepatic and enteric origin to the peripheral tissues and exports excessive lipids from cardiomyocytes as a protective mechanism for metabolic cardiomyopathy (Boren et al., 1998). Thus, similar to the observations in cardiomyocytes, the upregulation of APOA1 and APOB in the SYFs of broiler- and layer-type TCC hens (Cheng et al., unpublished) may represent a protective mechanism that involves exporting lipids into the circulation to avoid lipid peroxidation and lipotoxicity. Furthermore, significant upregulation of cytoskeleton proteins, such as ACTG1, ASMA, CKAP4, and PDLIM, and downregulation of MICAL3, SPARC, TPM1, TUBB, and 


\section{CTL}

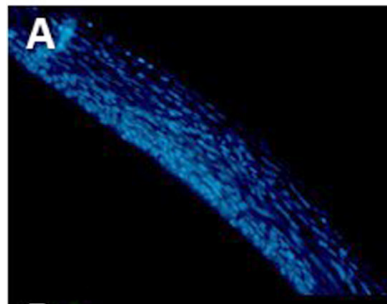

B

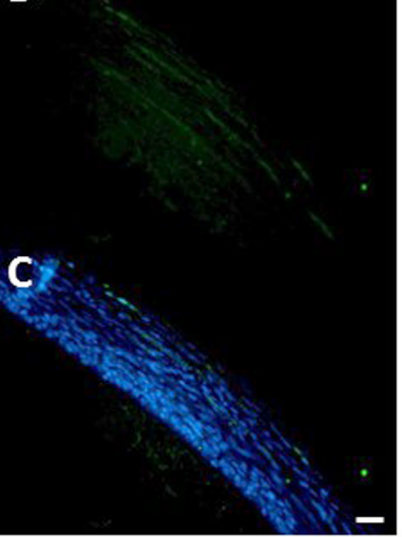

$\mathrm{H} 2 \mathrm{RO}$

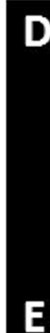

E

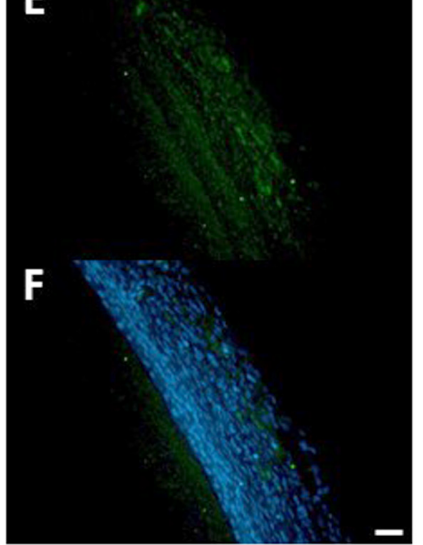

$\mathrm{H} 2 \mathrm{R} 2$

G

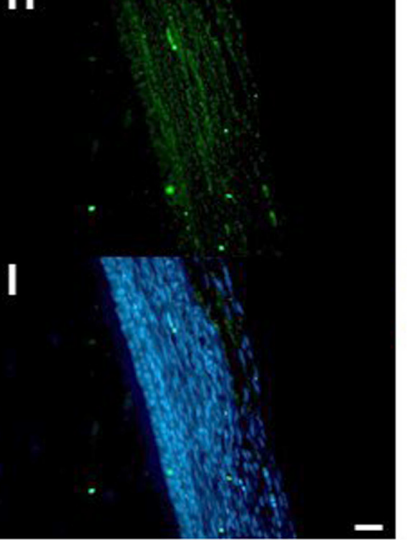

H2R6

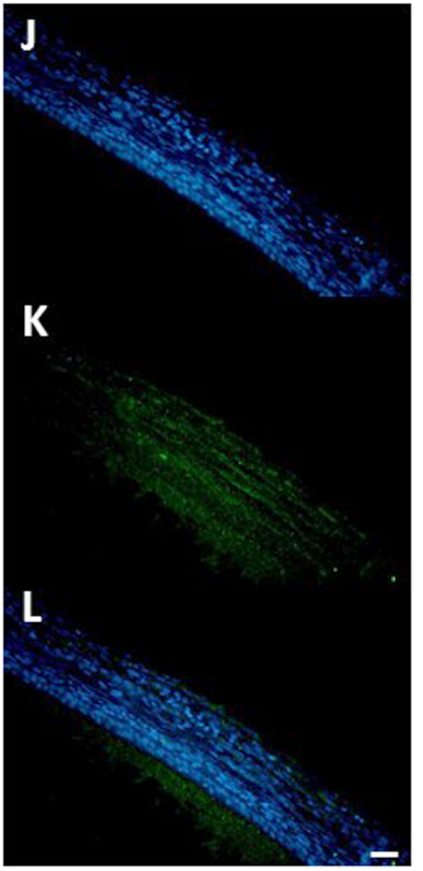

Fig. 5. Abundance of HSP70 in SYFs of broiler-type B strain TCCs. A, D, G, J, DAPI staining; B, E, H, K, HSP70 immunostaining; C, F, I, L, merged image. Bar $=20 \mu \mathrm{m}$.

\section{CTL}

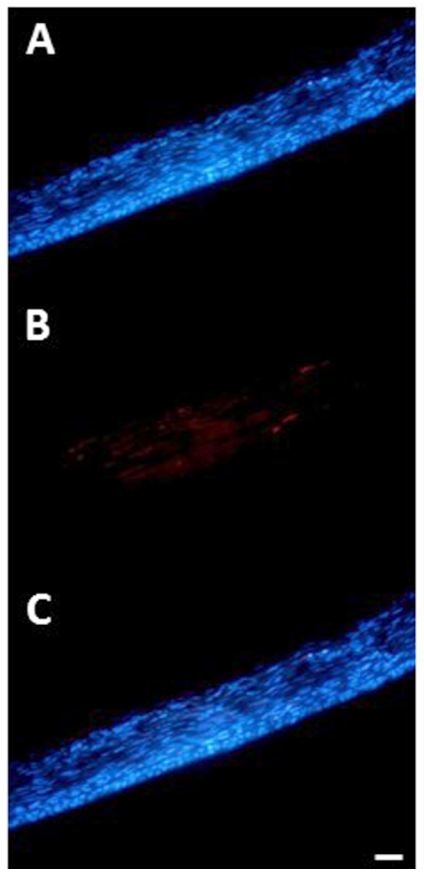

H2RO

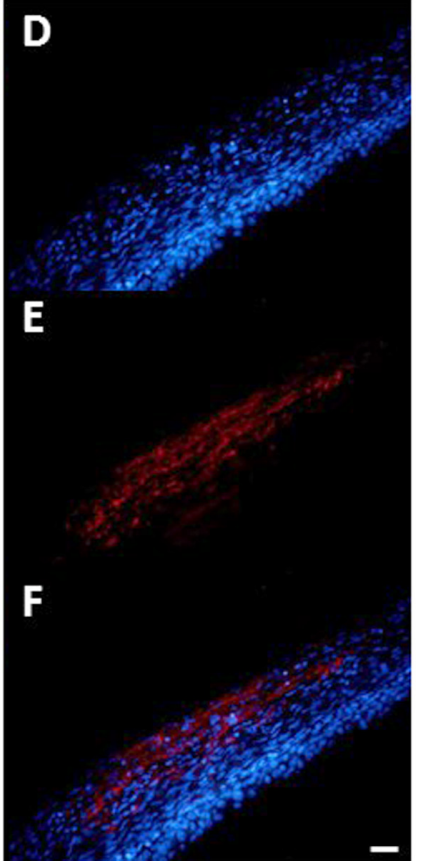

$\mathrm{H} 2 \mathrm{R} 2$

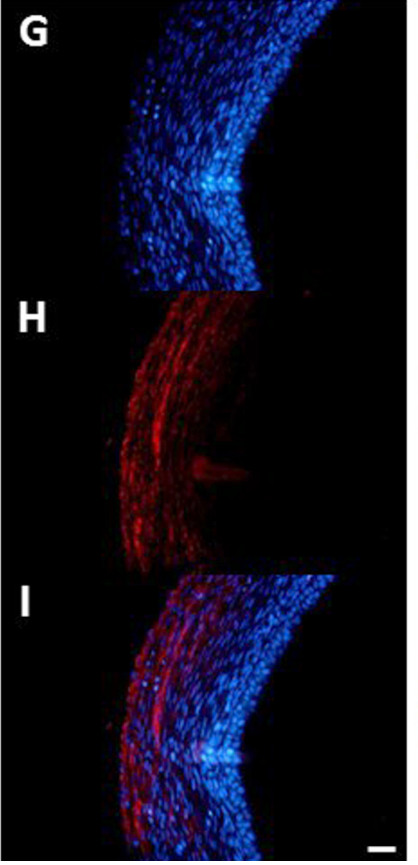

H2R6

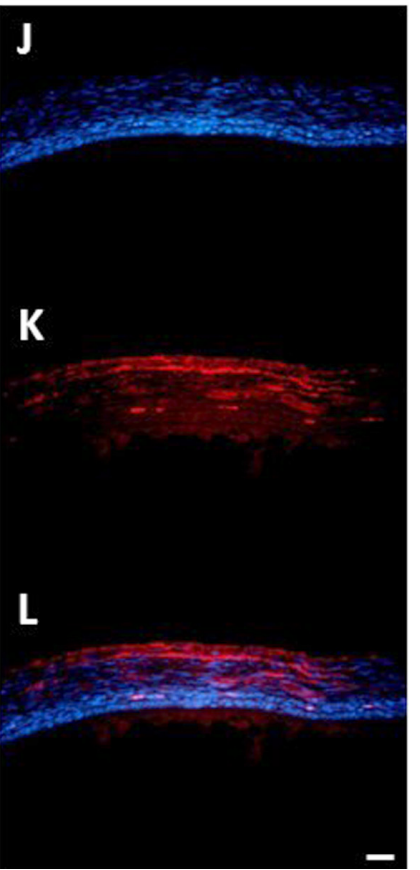

Fig. 6. Abundance of HSP25 in SYFs of broiler-type B strain TCCs. A, D, G, J, DAPI staining; B, E, H, K, HSP25 immunostaining; C, F, I, L, merged image. $B a r=20 \mu \mathrm{m}$. 


\section{Acute heat stress}

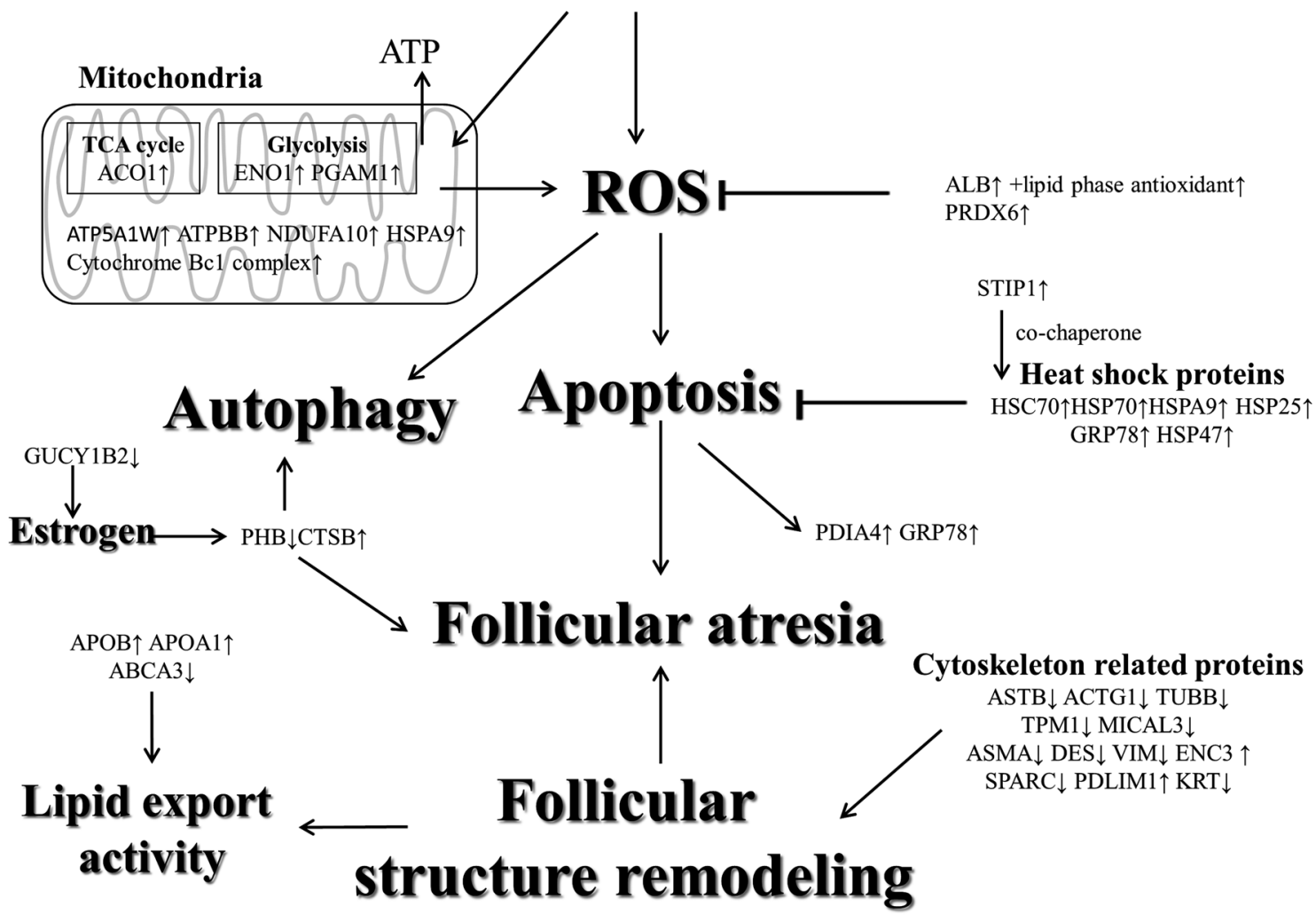

Fig. 7. Hypothetical mechanism of acute heat stress response in SYFs of broilertype B strain TCCs. The following proteins were upregulated in SYFs after acute heat stress: HSP25, HSP70, HSC70, HSPA9, and GRP78, which are related to protein folding and anti-apoptosis; PRDX6 and ALB, which are related to anti-oxidative stress activity; ACO1, ATP5A1W, ATP5B, HSPA9, HSC70, and NDUFA10, which are related to mitochondrial ATP synthase activity; and ENO1 and PGAM1, which are related to glycolysis. The significantly changed abundance of cytoskeleton-related proteins (ACTB, ACTG1, ASMA, DES, ENC3, KRT, MICAL3, PDLIM1, SPARC, TPM1, TUBB, and VIM) may disturb the normal structure of SYFs after acute heat stress. Cytoskeleton-related proteins involved in cellular differentiation and ovulatory process (DES, VIM, and ASMA), oxidative stress sensitivity (KRT), tissue repair (SPARC), and folliculogenesis (PHB) were decreased after acute heat stress. The abundances of PDIA4 and GRP78, which are related to apoptosis, were increased after acute heat stress in SYFs. APOA1 and APOB, which are associated with lipid transport activity, were upregulated and may remove excess lipids from SYFs. CTSB and PHB, which are autophagy-related proteins, were upregulated and may point to the induction of survival mechanisms in SYFs after acute heat stress. ROS, reactive oxygen species; HSP25, heat shock protein 25; HSP70, heat shock protein 70; HSC70, heat shock cognate 70; HSPA9, stress-70 protein, mitochondrial precursor; GRP78, $78 \mathrm{kDa}$ glucose-regulated protein precursor; PRDX6, peroxiredoxin-6; ALB, preproalbumin; ACO1, cytoplasmic aconitate hydratase; ATP5A1W, ATP synthase subunit alpha, mitochondrial isoform X2; ATP5B, ATP synthase subunit beta, mitochondrial precursor; NDUFA10, NADH dehydrogenase [ubiquinone] 1 alpha subcomplex subunit 10, mitochondrial; ENO1, alpha-enolase 1; PGAM1, phosphoglycerate mutase 1; ACTB, beta-actin; ACTG1, actin, cytoplasmic 1; ASMA, alpha-actin; DES, desmin; ENC3, ectodermal neural-cortex 3; KRT, keratin; MICAL3, microtubule-associated monoxygenase, calponin and LIM domain containing 3; PDLIM1, PDZ and LIM domain protein 1 isoform X4; SPARC, secreted protein acidic and rich in cysteine; TPM1, alphatropomyosin; TUBB, tubulin beta; VIM, vimentin; KRT, keratin; PHB, prohibitin; PDIA4, protein disulfide-isomerase A4; APOA1, apolipoprotein A-I; APOB, apolipoprotein B, CTSB, cathepsin B. 
VIM, were observed in broiler-type hen SYFs after acute heat stress (Table 1). The cytoskeleton is not only a structural element but is also involved in various cellular processes, such as transport, mitosis, secretion, migration, intercellular communication, and apoptosis (Chang and Goldman, 2004; Marceau et al., 2007; Goldman et al., 2008). The functions of DES, VIM, and smooth muscle actin in cellular differentiation and the ovulatory process have been demonstrated in several studies (Van Nassauw et al., 1992; Van Nassauw et al., 1993; Galou et al., 1997; Madekurozwa, 2012). KRT-positive granulosa cells have been shown to sense oxidative stress induced by oxidized low-density lipoprotein (Serke et al., 2010). PDLIM, the negative cytoskeleton organization regulator, is degraded by lysosomedependent autophagy to facilitate maintaining cytoskeleton organization (Shang et al., 2016). SPARC is necessary to maintain the integrity of follicular cells (Irles et al., 2017) and plays important roles in cell adhesion and angiogenesis, tumorigenesis, and tissue repair (Clark and Sage, 2008). Under gonadotropin stimulation, stable expression of TUBB in granulosa cells was shown to function in the transformation of cells into specific shapes (Ben-Ze'ev and Amsterdam, 1986). In summary, these cytoskeleton proteins induced by acute heat stress may be part of a dynamic process comprising cytoskeletal network disruption and re-assembly/ remodeling, which in turn may facilitate lipid export, prevent further peroxidation, and maintain cell functionality and liability, thus avoiding oxidative cell death and follicle atresia. This protective mechanism thus ensures a sufficient pool of SYFs for selection into the ovulation hierarchy.

\section{Possible Mechanisms of the Acute Heat Stress Response in} SYFs of Broiler-type TCCs

Based on the global regulation observed in the present proteomic study, we propose an acute heat stress response mechanism for the SYFs of broiler-type TCCs (Fig. 7). Heat stress upregulates several enzymes/proteins (ENO1, PGAM1, ACO1, ATP5A1W, ATP5B, cytochrome Bc1 complex, HSPA9, NDUFA10, and PGAM1) (Sugiura et al., 2005; Teltathum and Mekchay, 2009; Regassa et al., 2011; Morais et al., 2014; Iannaccone et al., 2015; Roth, 2015; Kamali Sangani et al., 2017) involved in the mitochondrial metabolic process of ATP production to meet the need for heat dissipation (Regassa et al., 2011; Morais et al., 2014; Iannaccone et al., 2015; Roth, 2015; Kamali Sangani et al., 2017), leading to ROS formation in the SYFs. These ROS then induce protein damage, cell apoptosis, and even follicle atresia. Consequently, several factors related to autophagy and cell survival, including CTSB and PDLIM1, are upregulated as a protective mechanism from oxidative insults after acute heat stress (Bebington et al., 2001; Man and Kanneganti, 2016; Shang et al., 2016). In addition, several defense factors related to anti-apoptotic protein chaperoning (HSP25, HSP70, HSC70, HSPA9, GRP78, and STIP1), hydrogen peroxide clearance (PRDX6), and lipid-phase antioxidant transporters (ALB) (Roche et al., 2008) in antioxidative defense are upregulated. The ATP-binding cassette transporter (ABCA3) (Chai et al., 2017), a lipid trans- porter in intracellular lipid homeostasis, is downregulated in SYFs by acute heat stress. However, proteins associated with cargo lipid export (APOA1 and APOB), and ALB for toxin/metabolite/peroxide clearance and delivery in the circulation to the kidneys for urine excretion, are increased to avoid lipid peroxidation and exacerbation of mitochondrial dysfunction. Moreover, acute heat stress alters cytoskeleton proteins (ACTB, ACTG1, ASMA, DES, ENC3, KRT, MICAL3, PDLIM1, SPARC, TPM1, TUBB, and VIM). These alterations represent a dynamic process comprising cytoskeletal network disruption and re-assembly/remodeling, and may facilitate lipid export, prevent further peroxidation, and maintain cell functionality and liability, thus avoiding oxidative cell death and follicle atresia. The decreased abundances of cytoskeleton proteins such as DES, SPARC, VIM, and ASMA in SYFs might lead to cellular differentiation and ovulatory process failure. In addition, the downregulation of GUCY1B2 may alter FSH-stimulated E2 production and decrease the regulation of $\mathrm{PHB}$, and thus, disturb the activity of tissue repair and folliculogenesis (Tafoya et al., 2004; Chowdhury et al., 2016). In addition, the abundances of PDIA4 and GRP78, related to ER stress and cell apoptosis (Tufo et al., 2014), were increased in SYFs after acute heat stress.

In conclusion, 2D-DIGE analysis revealed 76 proteins to be significantly differentially expressed after $2 \mathrm{~h}$ of acute heat stress in the SYFs of broiler-type TCC hens. Most of these proteins are involved in molecular binding, catalytic activity, and structural molecule activity, and they participate in metabolic processes, cellular processes, and cellular component organization or biogenesis. Proteins related to stress response, cell survival, mitochondrial metabolic process, antioxidative defense, cargo lipid export and delivery, toxin/ metabolite clearance and delivery, and cytoskeleton remodeling were upregulated after acute heat stress in the SYFs of broiler-type B strain TCCs. Additionally, PDIA4 and GRP78, which are involved in ER stress and cell apoptosis, were upregulated. These responses may represent a protective mechanism to maintain follicle cell integrity and survival, thus ensuring a sufficient pool of SYFs for selection into the ovulation hierarchy for successful egg production.

\section{Acknowledgments}

The authors thank the Ministry of Science and Technology (NSC102-2321-B-005-013; MOST 103-2321-B-005-010; MOST 104-2321-B-005-002) and the Ministry of Education (ATU Plan), Taiwan, for financial support.

\section{References}

Akbarian A, Michiels J, Degroote J, Majdeddin M, Golian A and De Smet S. Association between heat stress and oxidative stress in poultry; mitochondrial dysfunction and dietary interventions with phytochemicals. Journal of Animal Science and Biotechnology, 7: 37. 2016.

Barber DL, Sanders EJ, Aebersold R and Schneider WJ. The receptor for yolk lipoprotein deposition in the chicken oocyte. Journal of Biological Chemistry, 266: 18761-18770. 1991. 
Bebington C, Doherty FJ and Fleming SD. The possible biological and reproductive functions of ubiquitin. Human Reproduction Update, 7: 102-111. 2001.

Ben-Ze'ev A and Amsterdam A. Regulation of cytoskeletal proteins involved in cell contact formation during differentiation of granulosa cells on extracellular matrix. Proceedings of the National Academy of Sciences of the United States of America, 83: 2894-2898. 1986.

Beraldo FH, Thomas A, Kolisnyk B, Hirata PH, De Jaeger X, Martyn AC, Fan J, Goncalves DF, Cowan MF, Masood T, Martins VR, Gros R, Prado VF and Prado MA. Hyperactivity and attention deficits in mice with decreased levels of stressinducible phosphoprotein 1 (STIP1). Disease Models and Mechanisms, 8: 1457-1466. 2015.

Boren J, Veniant MM and Young SG. Apo B100-containing lipoproteins are secreted by the heart. Journal of Clinical Investigation, 101: 1197-1202. 1998.

Chai AB, Ammit AJ and Gelissen IC. Examining the role of ABC lipid transporters in pulmonary lipid homeostasis and inflammation. Respiratory Research, 18: 41. 2017.

Chang L and Goldman RD. Intermediate filaments mediate cytoskeletal crosstalk. Nature Reviews Molecular Cell Biology, 5: 601-613. 2004.

Chen CF, Shiue YL, Yen CJ, Tang PC, Chang HC and Lee YP. Laying traits and underlying transcripts, expressed in the hypothalamus and pituitary gland, that were associated with egg production variability in chickens. Theriogenology, 68: 1305-1315. 2007.

Cheng CY, Tu WL, Wang SH, Tang PC, Chen CF, Chen HH, Lee YP, Chen SE and Huang SY. Annotation of differential gene expression in small yellow follicles of a broiler-type strain of taiwan country chickens in response to acute heat stress. PLoS One, 10: e0143418. 2015.

Chowdhury I, Thomas K and Thompson WE. Prohibitin (PHB) roles in granulosa cell physiology. Cell and Tissue Research, 363: 19-29. 2016.

Clark CJ and Sage EH. A prototypic matricellular protein in the tumor microenvironment- where there's SPARC, there's fire. Journal of Cellular Biochemistry, 104: 721-732. 2008.

Davidson WS, Hazlett T, Mantulin WW and Jonas A. The role of apolipoprotein AI domains in lipid binding. Proceedings of the National Academy of Sciences of the United States of America, 93: 13605-13610. 1996.

Deeley RG, Mullinix DP, Wetekam W, Kronenberg HM, Meyers M, Eldridge JD and Goldberger RF. Vitellogenin synthesis in the avian liver. Vitellogenin is the precursor of the egg yolk phosphoproteins. Journal of Biological Chemistry, 250: 90609066. 1975.

Delavallee L, Cabon L, Galan-Malo P, Lorenzo HK and Susin SA. AIF-mediated caspase-independent necroptosis: a new chance for targeted therapeutics. IUBMB Life, 63: 221-232. 2011.

Finn RN. Vertebrate yolk complexes and the functional implications of phosvitins and other subdomains in vitellogenins. Biology of Reproduction, 76: 926-935. 2007.

Galou M, Gao J, Humbert J, Mericskay M, Li Z, Paulin D and Vicart P. The importance of intermediate filaments in the adaptation of tissues to mechanical stress: evidence from gene knockout studies. Biology of the Cell, 89: 85-97. 1997.

Goldman RD, Grin B, Mendez MG and Kuczmarski ER. Intermediate filaments: versatile building blocks of cell structure. Current Opinion in Cell Biology, 20: 28-34. 2008.

Hansen PJ. Effects of heat stress on mammalian reproduction.
Philosophical Transactions of the Royal Society B: Biological Sciences, 364: 3341-3350. 2009.

Iannaccone A, Giorgianni F, New DD, Hollingsworth TJ, Umfress A, Alhatem AH, Neeli I, Lenchik NI, Jennings BJ, Calzada JI, Satterfield S, Mathews D, Diaz RI, Harris T, Johnson KC, Charles S, Kritchevsky SB, Gerling IC, Beranova-Giorgianni S and Radic MZ. Circulating autoantibodies in age-related macular degeneration recognize human macular tissue antigens implicated in autophagy, immunomodulation, and protection from oxidative stress and apoptosis. PLOS ONE, 10: e0145323. 2015.

Irles P, Ramos S and Piulachs MD. SPARC preserves follicular epithelium integrity in insect ovaries. Developmental Biology, 422: 105-114. 2017.

Johnston JA, Ward CL and Kopito RR. Aggresomes: a cellular response to misfolded proteins. Journal of Cell Biology, 143: 1883-1898. 1998.

Kamali Sangani A, Masoudi AA and Vaez Torshizi R. Association of mitochondrial function and sperm progressivity in slow- and fast-growing roosters. Poultry Science, 96: 211-219. 2017.

Kuo YM, Shiue YL, Chen CF, Tang PC and Lee YP. Proteomic analysis of hypothalamic proteins of high and low egg production strains of chickens. Theriogenology, 64: 1490-1502. 2005.

Li GC. Heat shock proteins: role in thermotolerance, drug resistance, and relationship to DNA topoisomerases. NCI Monographs, 4: 99-103. 1987.

Li H, Benipal B, Zhou S, Dodia C, Chatterjee S, Tao JQ, Sorokina EM, Raabe T, Feinstein SI and Fisher AB. Critical role of peroxiredoxin 6 in the repair of peroxidized cell membranes following oxidative stress. Free Radical Biology and Medicine, 87: 356-365. 2015.

Li J, Gao H, Tian Z, Wu Y, Wang Y, Fang Y, Lin L, Han Y, Wu S, Haq I and Zeng S. Effects of chronic heat stress on granulosa cell apoptosis and follicular atresia in mouse ovary. Journal of Animal Science and Biotechnology, 7: 57. 2016.

Lin P, Yang Y, Li X, Chen F, Cui C, Hu L, Li Q, Liu W and Jin Y. Endoplasmic reticulum stress is involved in granulosa cell apoptosis during follicular atresia in goat ovaries. Molecular Reproduction and Development. 79: 423-432. 2012.

Liu JJ, Ma X, Cai LB, Cui YG and Liu JY. Downregulation of both gene expression and activity of Hsp27 improved maturation of mouse oocyte in vitro. Reproductive Biology and Endocrinology, 8: 47. 2010.

Luders J, Demand J and Hohfeld J. The ubiquitin-related BAG-1 provides a link between the molecular chaperones Hsc70/ Hsp70 and the proteasome. Journal of Biological Chemistry, 275: 4613-4617. 2000.

Madekurozwa MC. An immunohistochemical study of ovarian follicle histogenesis in the early post-hatch Japanese quail (Coturnix coturnix japonica). Anatomia, Histologia, Embryologia, 41: 79-86. 2012.

Man SM and Kanneganti TD. Regulation of lysosomal dynamics and autophagy by CTSB/cathepsin B. Autophagy, 12: 25042505. 2016.

Marceau N, Schutte B, Gilbert S, Loranger A, Henfling ME, Broers JL, Mathew J and Ramaekers FC. Dual roles of intermediate filaments in apoptosis. Experimental Cell Research, 313: 2265-2281. 2007.

Morais VA, Haddad D, Craessaerts K, De Bock PJ, Swerts J, Vilain S, Aerts L, Overbergh L, Grünewald A, Seibler P, Klein C, Gevaert K, Verstreken P and De Strooper B. PINK1 loss-of- 
function mutations affect mitochondrial complex I activity via NdufA10 ubiquinone uncoupling. Science, 344: 203-207. 2014.

Onagbesan O, Bruggeman V and Decuypere E. Intra-ovarian growth factors regulating ovarian function in avian species: a review. Animal Reproduction Science, 111: 121-140. 2009.

Regassa A, Rings F, Hoelker M, Cinar U, Tholen E, Looft C, Schellander $\mathrm{K}$ and Tesfaye D. Transcriptome dynamics and molecular cross-talk between bovine oocyte and its companion cumulus cells. BMC Genomics, 12: 57. 2011.

Rhee SG, Woo HA, Kil IS and Bae SH. Peroxiredoxin functions as a peroxidase and a regulator and sensor of local peroxides. Journal of Biological Chemistry, 287: 4403-4410. 2012.

Robinson FE and Etches RJ. Ovarian steroidogenesis during follicular maturation in the domestic fowl (Gallus domesticus). Biology of Reproduction, 35: 1096-1105. 1986.

Robinson FE, Etches RJ, Anderson-Langmuir CE, Burke WH, Cheng KW, Cunningham FJ, Ishii S, Sharp PJ and Talbot RT. Steroidogenic relationships of gonadotrophin hormones in the ovary of the hen (Gallus domesticus). General and Comparative Endocrinology, 69: 455-466. 1988.

Roche M, Rondeau P, Singh NR, Tarnus E and Bourdon E. The antioxidant properties of serum albumin. FEBS Letters, 582: 1783-1787. 2008.

Roth Z. Physiology and endocrinology symposium: Cellular and molecular mechanisms of heat stress related to bovine ovarian function. Journal of Animal Science, 93: 2034-2044. 2015.

Rozenboim I, Tako E, Gal-Garber O, Proudman JA and Uni Z. The effect of heat stress on ovarian function of laying hens. Poultry Science, 86: 1760-1765. 2007.

Sakatani M, Alvarez NV, Takahashi M and Hansen PJ. Consequences of physiological heat shock beginning at the zygote stage on embryonic development and expression of stress response genes in cattle. Journal of Dairy Science, 95: 30803091. 2012.

SAS. SAS/STAT User's Guide: Version 9.2 ed. SAS Institute Inc., Cary, NC, USA. 2010.

Schneider WJ. Lipoprotein receptors in oocyte growth. Clinical Investigation, 70: 385-390. 1992.

Serke H, Bausenwein J, Hirrlinger J, Nowicki M, Vilser C, Jogschies P, Hmeidan FA, Blumenauer V and SpanelBorowski $\mathrm{K}$ Granulosa cell subtypes vary in response to oxidized low-density lipoprotein as regards specific lipoprotein receptors and antioxidant enzyme activity. Journal of Clinical
Endocrinology and Metabolism, 95: 3480-3490. 2010.

Shang Y, Wang H, Jia P, Zhao H, Liu C, Liu W, Song Z, Xu Z, Yang L, Wang Y and Li W. Autophagy regulates spermatid differentiation via degradation of PDLIM1. Autophagy, 12: 1575-1592. 2016.

Sugiura K, Pendola FL and Eppig JJ. Oocyte control of metabolic cooperativity between oocytes and companion granulosa cells: energy metabolism. Developmental Biology, 279: 20-30. 2005.

Sun $\mathrm{C}$ and Zhang S. Immune-relevant and antioxidant activities of vitellogenin and yolk proteins in fish. Nutrients, 7: 8818-8829. 2015.

Tafoya MA, Chen JY, Stewart RL, Jr and Lapolt PS. Activation of soluble guanylyl cyclase inhibits estradiol production and cyclic AMP accumulation from cultured rat granulosa cells. Fertility and Sterility, 82 Supplement Issue 3: 1154-1159. 2004.

Taguchi $\mathrm{T}$ and Razzaque MS. The collagen-specific molecular chaperone HSP47: is there a role in fibrosis? Trends in Molecular Medicine, 13: 45-53. 2007.

Tan TQ, Ge C, Mi Y, Jin Y and Zhang C. Ginsenosides promote proliferation of granulosa cells from chicken prehierarchical follicles through PKC activation and up-regulated cyclin gene expression. Cell Biology International, 34: 769-775. 2010.

Teltathum T and Mekchay S. Proteome changes in Thai indigenous chicken muscle during growth period. International Journal of Biological Sciences, 5: 679-685. 2009.

Tufo G, Jones AW, Wang Z, Hamelin J, Tajeddine N, Esposti DD, Martel C, Boursier C, Gallerne C, Migdal C, Lemaire C, Szabadkai G, Lemoine A, Kroemer G and Brenner C The protein disulfide isomerases PDIA4 and PDIA6 mediate resistance to cisplatin-induced cell death in lung adenocarcinoma. Cell Death and Differentiation, 21: 685-695. 2014.

Van Nassauw L, Callebaut M, Harrisson F and Scheuermann DW. Smooth muscle cells in the walls of ovarian follicles in the Japanese quail. Cell and Tissue Research, 269: 49-56. 1992.

Van Nassauw L, Sys SU, Harrisson F and Callebaut M. In vitro study of the contractility of the wall of the preovulatory follicle in the Japanese quail. Biology of Reproduction, 49: 359-364. 1993.

Wang SH, Cheng CY, Chen CJ, Chen HH, Tang PC, Chen CF, Lee YP and Huang SY. Changes in protein expression in testes of L2 strain Taiwan country chickens in response to acute heat stress. Theriogenology, 82: 80-94. 2014. 